\title{
A LA BÚSQUEDA DE PERIODICIDADES EN LOS VALORES PLUVIOMÉTRICOS DEL NORTE GRANDE DE CHILE*
}

\author{
SEARCHING PERIODIC RAINFALL PATTERNS IN NORTHERN CHILE
}

\author{
Juan José Sanz Donaire ${ }^{* *}$ y Cristián Albornoz Espinoza ${ }^{* * *}$
}

\begin{abstract}
El presente trabajo constituye una primera aproximación a las periodicidades en los valores pluviométricos de las tres regiones más septentrionales de Chile, esto es, XV, I y II: Arica y Parinacota; Tarapacá; y Antofagasta, respectivamente. Tras haber sometido los datos a un rellenado de las series faltantes se ha podido operar en la determinación de componentes no aleatorios (aplicación de tests adecuados), sino rítmicos, en los valores. Se ha constatado que, lejos de una tendencia, excesivamente general, se destacan las repeticiones a los 3, 5, 8-9, 13 y 22 años que habrán de cotejarse con los posibles mecanismos de producción de lluvia ya establecidos.

Palabras claves: Norte de Chile, precipitación, periodicidad.
\end{abstract}

This paper is the first approach to periodicity patterns in the rainfall values of the northernmost regions of Chile: Arica and Parinacota, Tarapacá and Antofagasta. After completing as many series as possible with a bivariate regression model, once monthly data were stationarized, and some randomness tests were used to recognize its absence, periodic patterns of 3, 5, 8-9, 13 and 22 years were displayed, which have to be fitted to known precipitation mechanisms.

Key words: Northern Chile, precipitation, periodicity.

\section{Introducción}

Los estudios pluviométricos referidos al Norte de Chile son continuos, tanto desde la óptica preferentemente meteorológica (Aceituno, Garreaud, entre otros) como geográfica (Romero et al. 2013, Sarricolea y Romero, 2015), destacando los logros de la identificación de los componentes de procedencia amazónica mediante la vía peruana o boliviana, o bien pacífica. Así, Garreaud (2000) destaca que las variaciones de la troposfera baja son incapaces de explicar las amplias fluctuaciones interestacionales (estaciones astronómicas), por lo que probablemente sean los cambios en los transportes de humedad de las vertientes orientales, asociados a las anomalías de gran escala de la circulación, las que los provocan. A su vez Garreaud y Aceituno (2001) destacan la importancia del fenómeno del ENOS: humedad durante la Niña, sequedad en los períodos cálidos de El Niño, aunque solo a efectos de tendencia no predicción ni relación absoluta. Llegan a afirmar: in any case, the physical link between global-scale circulation anomalies (e.g. ENSO) and Altiplano rainfall anomalies is unclear (op. cit., pág. 2780).
Terminan aceptando que las anomalías locales de los vientos zonales arrojan gran dificultad en la predicción. Garreaud et al. (2003) creen que en todas las escalas temporales, desde la intraestacional hasta la glacial-interglacial, los episodios húmedos se relacionan con un flujo, el E en la circulación de altura. Se ha identificado la secuencia especialmente veraniega de los episodios de unos 5-7 días lluviosos, seguidos de una decena-quincena de secos (el doble que los registrados en las latitudes medias, aunque la mitad de la variabilidad intraestacional más prominentes en los trópicos), la relación de los momentos lluviosos con la Niña (que explicaría casi el 50\% de la variabilidad de la precipitación de los meses veraniegos: diciembre a febrero), aunque con cuantías bastante diferentes según las ocasiones (Niño anormalmente húmedo fue 1972/73; Niña muy seca 1988/89, descritos en el artículo como casual mechanism), y la impronta decadal de la anomalía de la temperatura de la superficie marina del Pacífico en latitudes tropicales. La variabilidad de la precipitación depende básicamente del aumento de los episodios húmedos dentro de la estación lluviosa que del crecimiento

\footnotetext{
* Proyecto FONDECYT N 1150701.

** Universidad Complutense de Madrid. Departamento de Análisis Geográfico Regional y Geografía Física. Madrid, España. Correo electrónico: jjsanzdo@ucm.es

*** Universidad de Heidelberg. Heidelberg Center para Latinoamérica. Heidelberg, Alemania. Correo electrónico: albornoz@ uni-heidelberg.de
} 
de la intensidad de la lluvia (con aceptación de conceptos más actualistas que catastrofistas, pág. 14). A su vez, Romero et al. (2013) afirman que "la falta de estaciones meteorológicas de largo plazo constituye una limitación insuperable para referirse a las tendencias de cambio y variabilidad climática en el desierto de Atacama" (pág. 12), pues solo 2 tienen, al menos, 30 años y no son altiplánicas sino costeras (Iquique y Arica). Al propio tiempo y en referencia a las precipitaciones, aseguran: "los datos existentes no solo impiden registrar tendencia alguna de variaciones interanuales, sino que implican además una altísima incertidumbre sobre la existencia de agua superficial, y por ello, un aumento creciente de la presión sobre los recursos subterráneos, muchos de los cuales son de carácter fósil y, por ello, no renovables" (pág. 25). "El examen de las series y su comparación revela una gran complejidad de las causas de las condiciones climáticas generadoras de precipitaciones y sequías" (pág. 30), destacando la irregularidad por el topoclima. Por nuestra parte algo hemos querido desvelar de los comportamientos rítmicos en las precipitaciones chilenas (Sanz Donaire, 2012), aunque con resultados exiguos en las áreas más extremadamente áridas. Intentar poner de manifiesto pautas repetitivas es la meta del presente estudio.

\section{Materiales y método}

La obtención de los datos ha planteado algunas dificultades, que en gran medida se despejaron al recibir de la Dirección General de Agua del Ministerio de Obras Públicas, DGA del MOP, los datos mensuales hasta la finalización del año 2015. Previamente se había acudido a otras fuentes, como los anuarios estadísticos nacionales y la NOAA ( $w w w$. ncdc.noaa.gov/data-access), datos estos últimos que reproducen los enviados por los organismos nacionales chilenos, si bien en ciertas series de las capitales, Arica, Iquique y Antofagasta, significan la posibilidad de anticipar en alguna década el inicio de las series. En la presente elaboración se ha manejado el tiempo civil, siendo los años computados desde enero a diciembre. La unidad anual es indicativa de un ciclo de inequívoca significación meteorológica y climática, cosa que no se puede afirmar de los meses, cuya definición lunar no tiene las mismas connotaciones respecto del tiempo atmosférico.

La existencia de numerosas lagunas se intentó paliar mediante la obtención de datos de otras fuentes, como el portal "Tu Tiempo" ( $w w w$. tutiempo.net/clima), que también procesa los datos nacionales enviados, pero que, de modo al inicio incomprensible, producía notables discrepancias con los restantes datos. Se llegó a pensar en que se hubiera cursado una orden en el procesado de los mismos para evitar los outliers, los valores estridentes, pero en comunicación mantenida con quienes se responsabilizan del cuidado de esta página web se obtuvo como respuesta que el transvase de datos se hacía de modo automático, por lo que debe achacarse a un error en el reconocimiento óptico de los caracteres, OCR.

Los datos con los que se ha contado, pues, para el trabajo son fundamentalmente debidos a la DGA, si bien antecedidos - cuando ello era posible y creíble- por los datos de la NOAA. Se ha optado por respetar las series enteras de registro, sin referirlas todas a un período unificado, aunque ello signifique ciertas complicaciones en el manejo de las mismas, máxime debido también a que la gran mayoría de las estaciones presenta interrupciones en la toma de datos. La lista, ordenada alfabéticamente por siglas, de las estaciones procesadas aparece en la Tabla 1, con indicación de algunos datos característicos, a los que habremos de referirnos con posterioridad.

La Tabla 1 recoge la identificación cartográfica mediante dos letras, que se emplearán después, la pertenencia a las distintas regiones $(\mathrm{Rg}=$ número en romanos), provincias (Pr: Parinacota $=\mathrm{Pa}$, Iquique $=$ Iq, Arica $=$ Ar, El Loa $=$ Lo, Tocopilla $=$ Tc y Antofagasta $=$ An), comunas (General Lagos $=$ GLg, Pica $=$ Pic; Camiña $=$ Cañ Putre $=$ Put Camarones $=$ Cam; Colchane $=$ Col, Pozo Almonte $=$ PAl; María Elena $=$ MEl; Taltal $=$ Tal; Antofagasta $=$ Ant; Tocopilla $=$ Tcp $;$ Calama $=$ $\mathrm{Cal}$; Ollagüe $=$ Oll; San Pedro de Atacama $=$ SPA y Sierra Gorda $=$ SGd), la clasificación según tres tipos de localización expuestos más abajo [(1) costa y oasis aledaños; (2) quebradas de la precordillera, y (3) altiplanos volcánicos]; $\mathrm{A}=$ años; $\mathrm{Ac}=$ años completos; $\bar{x}=$ media en $\mathrm{mm} ; \mathrm{CV}=$ coeficiente de variación y $\mathrm{CS}=$ coeficiente de sesgo para los datos originales. Las mismas siglas con comilla (prima) para datos completados. El valor de -100 se reserva para ausencia de dato o cálculo.

Por su parte la repartición de las estaciones es tan dispar (Mapa 1) como el hábitat humano que se concentra en los tres espacios mencionados: 1) la costa, con 15 estaciones hasta $365 \mathrm{~m}$ de altitud; 2) la precordillera o sierra en sus quebradas profundas, 
Tabla 1. Estaciones pluviométricas y sus características.

\begin{tabular}{|c|c|c|c|c|c|c|c|c|c|c|c|c|c|c|}
\hline Estación & Id & $\mathbf{R g}$ & $\operatorname{Pr}$ & $\mathrm{Cmn}$ & $\mathrm{T}$ & A & Ac & $\bar{x}$ & $\mathrm{CV}$ & $\mathrm{CS}$ & Ac' & $\bar{x}$, & $\mathrm{CV}^{\prime}$ & CS' \\
\hline Arica Chacalluta & $\mathrm{AC}$ & $\mathrm{XV}$ & $\mathrm{Ar}$ & $\mathrm{Ar}$ & 1 & 96 & 79 & 1,05 & 1,7 & 2,4 & 90 & 1,04 & 1,63 & 2,4 \\
\hline Altos del Huasco & $\mathrm{AH}$ & $\mathrm{I}$ & $\mathrm{Iq}$ & Pic & 3 & 5 & 3 & 70,46 & 0,9 & 1,7 & 3 & 70,46 & 0,94 & 1,69 \\
\hline Río Salado A J Curti & $\mathrm{AJ}$ & II & Lo & $\mathrm{Cal}$ & 3 & 2 & 0 & -100 & -100 & -100 & 0 & -100 & -100 & -100 \\
\hline Alcérreca & $\mathrm{AL}$ & XV & $\mathrm{Pa}$ & GLg & 3 & 45 & 38 & 208,48 & 0,5 & 0,3 & 43 & 207,4 & 0,49 & 0,35 \\
\hline Amincha & $\mathrm{AM}$ & II & Lo & Oll & 3 & 4 & 0 & -100 & -100 & -100 & 0 & -100 & -100 & -100 \\
\hline Antofagasta & AN & II & An & Ant & 1 & 65 & 63 & 10,8 & 2,1 & 3,9 & 63 & 10,8 & 2,1 & 3,92 \\
\hline Arica Oficina & $\mathrm{AO}$ & $\mathrm{XV}$ & $\mathrm{Ar}$ & $\mathrm{Ar}$ & 1 & 42 & 39 & 1,03 & 1,3 & 1,2 & 90 & 1,27 & 0,82 & 0,72 \\
\hline Apamilca & $\mathrm{AP}$ & $\mathrm{I}$ & $\mathrm{Iq}$ & Cañ & 2 & & & & & & & & & \\
\hline Sifón Ayquina & $\mathrm{AQ}$ & II & Lo & $\mathrm{Cal}$ & 3 & 3 & 2 & -100 & -100 & -100 & 2 & -100 & -100 & -100 \\
\hline Ascotán & AS & II & Lo & Oll & 3 & 42 & 33 & 69,62 & 0,7 & 1 & 43 & 68,07 & 0,63 & 1,04 \\
\hline San Pedro de Atacama & AT & II & Lo & SPA & 2 & 57 & 29 & 29,46 & 1 & 1,5 & 53 & 29,78 & 0,76 & 1,55 \\
\hline Aguas Verdes & $\mathrm{AV}$ & II & An & Tal & 2 & 29 & 0 & -100 & -100 & -100 & 46 & 10,83 & 1,01 & 0,95 \\
\hline Ayquina & $\mathrm{AY}$ & II & Lo & $\mathrm{Cal}$ & 3 & 49 & 41 & 41,05 & 1,1 & 1,9 & 44 & 40,65 & 1,07 & 2,03 \\
\hline Azapa & $\mathrm{AZ}$ & $\mathrm{XV}$ & $\mathrm{Ar}$ & $\mathrm{Ar}$ & 1 & 50 & 39 & 0,8 & 2,1 & 2,9 & 45 & 0,97 & 1,72 & 2,44 \\
\hline El Buitre Aeródromo & $\mathrm{BA}$ & $\mathrm{XV}$ & $\mathrm{Ar}$ & $\mathrm{Ar}$ & 1 & 27 & 25 & 0,94 & 1,7 & 1,3 & 45 & 1,08 & 1,22 & 1,16 \\
\hline Belén & $\mathrm{BE}$ & $\mathrm{XV}$ & $\mathrm{Pa}$ & Put & 2 & 78 & 41 & 156,7 & 0,8 & 2,2 & 48 & 153 & 0,75 & 2,17 \\
\hline Baquedano & $\mathrm{BQ}$ & II & An & SGd & 2 & 41 & 29 & 1,33 & 2,1 & 2,7 & 46 & 2,36 & 1,65 & 2,24 \\
\hline Río Siloli antes B. T. Fcab & $\mathrm{BT}$ & II & Lo & Oll & 3 & 4 & 1 & -100 & -100 & -100 & 1 & -100 & -100 & -100 \\
\hline Coyacagua & $\mathrm{CA}$ & I & $\mathrm{Iq}$ & Pic & 3 & 55 & 51 & 137,67 & 0,6 & 1 & 52 & 138,2 & 0,57 & 0,98 \\
\hline Cebollar & $\mathrm{CB}$ & II & Lo & Oll & 3 & 32 & 23 & 60,03 & 0,7 & 0,9 & 43 & 61,73 & 0,55 & 0,75 \\
\hline Cotacotani & $\mathrm{CC}$ & $\mathrm{XV}$ & $\mathrm{Pa}$ & Put & 3 & 55 & 45 & 406,41 & 0,4 & 0,2 & 53 & 391 & 0,36 & 0,21 \\
\hline Codpa Retén & $\mathrm{CD}$ & $\mathrm{XV}$ & $\mathrm{Ar}$ & Cam & 2 & 55 & 48 & 16,73 & 0,9 & 1,3 & 48 & 16,73 & 0,94 & 1,33 \\
\hline Caritaya Embalse & $\mathrm{CE}$ & $\mathrm{XV}$ & $\mathrm{Ar}$ & Cam & 2 & 34 & 2 & -100 & -100 & -100 & 2 & -100 & -100 & -100 \\
\hline Collahuasi & $\mathrm{CH}$ & $\mathrm{I}$ & $\mathrm{Iq}$ & Pic & 3 & 21 & 16 & 162,34 & 0,4 & 0,7 & 16 & 162,3 & 0,44 & 0,73 \\
\hline Chiuchiu & $\mathrm{CI}$ & II & Lo & $\mathrm{Cal}$ & 3 & 42 & 37 & 5,65 & 1 & 1,6 & 46 & 5,56 & 0,94 & 1,56 \\
\hline Calama & $\mathrm{CL}$ & II & Lo & $\mathrm{Cal}$ & 2 & 51 & 36 & 4,26 & 1,2 & 1,3 & 46 & 4,34 & 1,09 & 1,22 \\
\hline Camiña & $\mathrm{CM}$ & I & $\mathrm{Iq}$ & Cañ & 2 & 45 & 29 & 42,04 & 1,3 & 1,4 & 40 & 41,9 & 1,18 & 1,41 \\
\hline Cancosa & $\mathrm{CN}$ & $\mathrm{I}$ & $\mathrm{Iq}$ & Pic & 3 & 37 & 25 & 172,73 & 0,7 & 0,8 & 35 & 163 & 0,67 & 0,94 \\
\hline Central Chapiquiña & $\mathrm{CN}$ & $\mathrm{XV}$ & $\mathrm{Pa}$ & Put & 2 & 53 & 41 & 153,91 & 0,7 & 1 & 48 & 163,7 & 0,61 & 0,8 \\
\hline Copaquire & $\mathrm{CO}$ & I & $\mathrm{Iq}$ & Pic & 2 & 35 & 25 & 81,22 & 1,4 & 4 & 32 & 80,6 & 1,28 & 4,27 \\
\hline Coposa & $\mathrm{CP}$ & I & $\mathrm{Iq}$ & Pic & 3 & 34 & 18 & 100,95 & 0,8 & 1,3 & 30 & 99,56 & 0,69 & 1,42 \\
\hline Caquena & CQ & $\mathrm{XV}$ & $\mathrm{Pa}$ & Put & 3 & 46 & 32 & 413,2 & 0,4 & 0,1 & 53 & 407,8 & 0,36 & 0,17 \\
\hline Camar & $\mathrm{CR}$ & II & Lo & SPA & 3 & 37 & 36 & 33,64 & 1 & 1,2 & 40 & 36,54 & 0,87 & 0,94 \\
\hline Caspana & $\mathrm{CS}$ & II & Lo & $\mathrm{Cal}$ & 3 & 38 & 34 & 82,18 & 1 & 1,9 & 44 & 79,01 & 1,03 & 1,92 \\
\hline Cupo & $\mathrm{CU}$ & II & Lo & $\mathrm{Cal}$ & 3 & 38 & 33 & 71,05 & 1,1 & 1,5 & 43 & 81,99 & 0,98 & 1,23 \\
\hline Conchi Viejo & $\mathrm{CV}$ & II & Lo & $\mathrm{Cal}$ & 3 & 43 & 34 & 40,19 & 1 & 2,5 & 42 & 38,6 & 0,95 & 2,72 \\
\hline
\end{tabular}




\begin{tabular}{|c|c|c|c|c|c|c|c|c|c|c|c|c|c|c|}
\hline Estación & Id & $\mathbf{R g}$ & $\operatorname{Pr}$ & $\mathrm{Cmn}$ & $\mathrm{T}$ & A & Ac & $\bar{x}$ & $\mathrm{CV}$ & CS & Ac' & $\bar{x}$ & CV' & CS' \\
\hline Colchane T Isluga & $\mathrm{CX}$ & I & Iq & Col & 3 & 41 & 32 & 123,87 & 0,7 & 1,1 & 36 & 122,5 & 0,66 & 1,19 \\
\hline Cuya & $\mathrm{CY}$ & $\mathrm{XV}$ & $\mathrm{Ar}$ & $\mathrm{Ar}$ & 2 & 15 & 10 & 0 & -100 & -100 & 43 & 0,76 & 1,46 & 2,25 \\
\hline $\begin{array}{l}\text { Río Desaguadero } \\
\text { Cotacotani }\end{array}$ & DG & $\mathrm{XV}$ & $\mathrm{Pa}$ & Put & 3 & 1 & 0 & -100 & -100 & -100 & 1 & 0 & -100 & -100 \\
\hline Diablo Marca & DM & I & $\mathrm{Iq}$ & Pic & 3 & 27 & 2 & -100 & -100 & -100 & 2 & -100 & -100 & -100 \\
\hline $\begin{array}{l}\text { Río Loa salida embalse } \\
\text { Conchi }\end{array}$ & $\mathrm{EC}$ & II & Lo & Cal & 3 & 4 & 2 & -100 & -100 & -100 & 2 & -100 & -100 & -100 \\
\hline Escondida & $\mathrm{ED}$ & II & An & Ant & 1 & 1 & 0 & -100 & -100 & -100 & 0 & -100 & -100 & -100 \\
\hline Enquelca Ex Caraguano & EN & I & $\mathrm{Iq}$ & $\mathrm{Col}$ & 3 & 31 & 23 & 118,57 & 0,6 & 0,4 & 31 & 110,7 & 0,59 & 0,67 \\
\hline Esquiña & EÑ & $\mathrm{XV}$ & $\mathrm{Ar}$ & Cam & 2 & 41 & 39 & 42,07 & 0,9 & 1,6 & 47 & 46,47 & 0,86 & 1,22 \\
\hline Esmeralda & ES & $\mathrm{I}$ & $\mathrm{Iq}$ & Pic & 2 & 14 & 2 & -100 & -100 & -100 & 2 & -100 & -100 & -100 \\
\hline El Tatio & ET & II & Lo & $\mathrm{Cal}$ & 3 & 39 & 31 & 149,5 & 0,7 & 1,1 & 41 & 42,83 & 1,12 & 1,36 \\
\hline Huara Fte. Baquedano & FB & I & $\mathrm{Iq}$ & Cañ & 1 & 23 & 12 & 1,13 & 2 & 2,7 & 40 & 1,5 & 1,14 & 1,79 \\
\hline Río Grande & GD & II & Lo & SPA & 3 & 39 & 35 & 75,42 & 0,8 & 1 & 40 & 72,28 & 0,81 & 1,02 \\
\hline Guallatire & GR & $\mathrm{XV}$ & $\mathrm{Pa}$ & Put & 3 & 47 & 40 & 255,51 & 0,5 & 1 & 48 & 272 & 0,5 & 1,02 \\
\hline Guatacondo DGA & $\mathrm{GU}$ & I & Iq & PAl & 2 & 39 & 36 & 21,66 & 1,3 & 2,3 & 37 & 22,23 & 1,29 & 2,18 \\
\hline Humapalca & $\mathrm{HM}$ & $\mathrm{XV}$ & $\mathrm{Pa}$ & GLg & 3 & 45 & 42 & 285,25 & 0,5 & 1,3 & 43 & 289,3 & 0,53 & 1,17 \\
\hline Huaytani & $\mathrm{HU}$ & I & Iq & Col & 3 & 34 & 27 & 135,48 & 0,9 & 1,6 & 32 & 142,8 & 0,81 & 1,35 \\
\hline Isla Blanca & IB & $\mathrm{XV}$ & $\mathrm{Pa}$ & Put & 3 & 20 & 16 & 356,91 & 0,5 & 0,9 & 53 & 353,2 & 0,4 & 0,76 \\
\hline Imilac & $\mathrm{IM}$ & II & An & Ant & 3 & 6 & 4 & 1,75 & 2 & 2 & 4 & 1,75 & 2 & 2 \\
\hline Inacaliri & IN & II & Lo & Cal & 3 & 47 & 39 & 125,14 & 0,7 & 0,9 & 43 & 122,8 & 0,73 & 0,87 \\
\hline Iquique & IQ & I & Iq & $\mathrm{Iq}$ & 1 & 117 & 117 & 2,58 & 3,4 & 8,1 & 117 & 2,58 & 3,37 & 8,1 \\
\hline La Chimba & $\mathrm{LB}$ & II & An & Ant & 1 & 1 & 0 & -100 & -100 & -100 & 0 & -100 & -100 & -100 \\
\hline Las Cuevas Conaf & $\mathrm{LC}$ & $\mathrm{XV}$ & $\mathrm{Pa}$ & Put & 2 & 3 & 1 & -100 & -100 & -100 & 1 & -100 & -100 & -100 \\
\hline Lagunillas Pampa Lirima & LG & I & $\mathrm{Iq}$ & Pic & 3 & 34 & 27 & 133,32 & 0,5 & 1,9 & 36 & 135,8 & 0,51 & 1,57 \\
\hline Lluta & LL & $\mathrm{XV}$ & $\mathrm{Ar}$ & $\mathrm{Ar}$ & 1 & 28 & 10 & 0,05 & 3,2 & 3,2 & 10 & 0,05 & 3,16 & 3,16 \\
\hline Lequena & LQ & II & Lo & Cal & 3 & 43 & 38 & 92,74 & 1,4 & 3 & 43 & 91,62 & 1,35 & 2,89 \\
\hline Linzor & $\mathrm{LZ}$ & II & Lo & $\mathrm{Cal}$ & 3 & 43 & 32 & 178,03 & 0,6 & 0,7 & 39 & 168,5 & 0,61 & 0,91 \\
\hline Murmutane & MM & $\mathrm{XV}$ & $\mathrm{Pa}$ & Put & 2 & 18 & 5 & 170,99 & 0,6 & -1 & 5 & 171 & 0,61 & $-0,98$ \\
\hline Mamiña & MÑ & I & $\mathrm{Iq}$ & PAl & 2 & 30 & 25 & 27,39 & 0,9 & 0,8 & 37 & 28,39 & 0,759 & 0,7 \\
\hline Monturaqui & MO & II & An & Ant & 3 & 6 & 5 & 58,5 & 0,7 & 0,5 & 5 & 58,5 & 0,68 & 0,52 \\
\hline Missituni & MS & $\mathrm{XV}$ & $\mathrm{Pa}$ & Put & 3 & 8 & 0 & -100 & -100 & -100 & 8 & 0 & -100 & -100 \\
\hline Parca & $\mathrm{MU}$ & I & $\mathrm{Iq}$ & PAl & 2 & 39 & 33 & 29,36 & 1,1 & 2,2 & 40 & 30 & 1,04 & 2,09 \\
\hline Mocha & MX & I & Iq & Cañ & 2 & 28 & 22 & 29,74 & 1,4 & 2,7 & 36 & 31,06 & 1,16 & 2,63 \\
\hline Ollagüe & $\mathrm{OG}$ & II & Lo & Oll & 3 & 45 & 19 & 81,77 & 0,8 & 0,6 & 43 & 82,79 & 0,65 & 0,46 \\
\hline Ojos San Pedro & OS & II & Lo & $\mathrm{Cal}$ & 3 & 47 & 32 & 59,08 & 0,7 & 0,8 & 43 & 62,93 & 0,77 & 0,84 \\
\hline Pacollo & $\mathrm{PA}$ & $\mathrm{XV}$ & $\mathrm{Pa}$ & Put & 3 & 22 & 18 & 210,64 & 0,6 & 0,7 & 18 & 210,6 & 0,55 & 0,69 \\
\hline Parinacota Conaf DGA & PC & XV & $\mathrm{Pa}$ & Put & 3 & 58 & 38 & 354,82 & 0,4 & $-0,2$ & 77 & 362,6 & 0,32 & 0,089 \\
\hline
\end{tabular}




\begin{tabular}{|c|c|c|c|c|c|c|c|c|c|c|c|c|c|c|}
\hline Estación & Id & $\mathbf{R g}$ & $\operatorname{Pr}$ & $\mathrm{Cmn}$ & $\mathbf{T}$ & $\mathbf{A}$ & Ac & $\bar{x}$ & $\mathrm{CV}$ & CS & Ac' & $\bar{x}$ & CV' & CS' \\
\hline Parinacota Ex Endesa & PE & XV & $\mathrm{Pa}$ & Put & 3 & 33 & 26 & 329,37 & 0,4 & 0,3 & 51 & 321,1 & 0,36 & 0,23 \\
\hline Pampa Lirima DCP & PL & I & $\mathrm{Iq}$ & Pic & 3 & 13 & 10 & 114,34 & 0,7 & 1,3 & 36 & 121,1 & 0,46 & 1,12 \\
\hline Pumire & PM & I & Iq & $\mathrm{Col}$ & 2 & 60 & 50 & 258,5 & 0,8 & 0,5 & 50 & 258,5 & 0,77 & 0,46 \\
\hline Peine & PN & II & Lo & SPA & 3 & 42 & 39 & 20,05 & 0,9 & 1,3 & 40 & 19,59 & 0,97 & 1,36 \\
\hline R. Collacagua Peñablanca & PÑ & I & Iq & Pic & 3 & 26 & 0 & -100 & -100 & -100 & 26 & 0 & -100 & -100 \\
\hline Poroma & $\mathrm{PO}$ & I & $\mathrm{Iq}$ & PAl & 2 & 48 & 34 & 45,35 & 0,9 & 1,5 & 37 & 44,32 & 0,84 & 1,58 \\
\hline Puquios & PQ & XV & $\mathrm{Ar}$ & $\mathrm{Ar}$ & 2 & 7 & 3 & 56,16 & 0,5 & 0 & 3 & 56,16 & 0,45 & 0,029 \\
\hline Parshall $n^{0} 2$ & PS & II & Lo & Cal & 3 & 47 & 39 & 30,01 & 0,9 & 1,4 & 44 & 30,15 & 0,85 & 1,27 \\
\hline Putre & PT & XV & $\mathrm{Pa}$ & Put & 2 & 48 & 38 & 197,08 & 0,6 & 0,6 & 38 & 197,1 & 0,55 & 0,55 \\
\hline Puchultiza & $\mathrm{PZ}$ & I & $\mathrm{Iq}$ & Col & 3 & 7 & 6 & 173,91 & 0,8 & 1 & 6 & 173,9 & 0,8 & 1,01 \\
\hline Quinchamale & $\mathrm{QM}$ & II & Lo & Cal & 3 & 21 & 17 & 25,24 & 1,2 & 1,9 & 42 & 26,32 & 0,89 & 1,82 \\
\hline Quillagua & QU & II & To & MEl & 2 & 46 & 36 & 0,2 & 2,8 & 3,8 & 46 & 0,27 & 2,05 & 3,05 \\
\hline R. Caracarani Humapalca & $\mathrm{RC}$ & XV & $\mathrm{Pa}$ & GLg & 3 & 3 & 0 & -100 & -100 & -100 & 3 & 0 & -100 & -100 \\
\hline R. Guallatire Guallatire & $\mathrm{RG}$ & XV & $\mathrm{Pa}$ & Put & 3 & 28 & 0 & -100 & -100 & -100 & 28 & 0 & -100 & -100 \\
\hline R. Huatacondo Copaquire & $\mathrm{RH}$ & I & $\mathrm{Iq}$ & Pic & 2 & 5 & 4 & 56,25 & 0,8 & 1,5 & 4 & 56,25 & 0,84 & 1,52 \\
\hline Cerro Colorado & RJ & I & $\mathrm{Iq}$ & PAl & 2 & 23 & 20 & 16,59 & 0,8 & 0,7 & 40 & 20,69 & 0,613 & 0,13 \\
\hline R. Lluta en Alcérreca & RL & XV & $\mathrm{Pa}$ & GLg & 3 & 15 & 12 & 144,77 & 0,4 & 0,5 & 42 & 138,7 & 0,34 & 0,38 \\
\hline R. Loa represa Lequena & $\mathrm{RQ}$ & II & Lo & Cal & 3 & 15 & 13 & 66,59 & 0,8 & 1,5 & 42 & 75,47 & 0,66 & 1,68 \\
\hline R. Salado sifón Ayquina & $\mathrm{RS}$ & II & Lo & Cal & 3 & 15 & 13 & 26,27 & 0,9 & 2,2 & 39 & 29,67 & 0,66 & 1,52 \\
\hline R. Ticnamar Angostura & RT & $\mathrm{XV}$ & $\mathrm{Pa}$ & Put & 2 & 10 & 4 & 55,89 & 1,3 & 1,8 & 38 & 68,82 & 0,61 & 1,32 \\
\hline Sagasca & SA & I & Iq & PAl & 2 & 22 & 14 & 0,61 & 1,8 & 1,8 & 36 & 0,91 & 1,15 & 1,43 \\
\hline Q. Tarapacá Sibaya & $\mathrm{SB}$ & I & $\mathrm{Iq}$ & Cañ & 2 & 12 & 8 & 43,43 & 0,6 & 0,4 & 8 & 43,43 & 0,6 & 0,38 \\
\hline Socaire & $\mathrm{SC}$ & II & Lo & SPA & 3 & 42 & 35 & 42,09 & 0,9 & 1,2 & 40 & 42,91 & 0,9 & 1,11 \\
\hline Salado embalse & SE & II & Lo & Cal & 3 & 41 & 34 & 72,91 & 1 & 2 & 43 & 80,09 & 1 & 1,86 \\
\hline Sierra Gorda & SG & II & To & MEl & 2 & 36 & 17 & 0,88 & 2,3 & 2,7 & 17 & 0,88 & 2,28 & 2,68 \\
\hline Salar Huasco & $\mathrm{SH}$ & I & $\mathrm{Iq}$ & Pic & 3 & 2 & 0 & -100 & -100 & -100 & 2 & 0 & -100 & -100 \\
\hline Silala & SI & II & Lo & Oll & 3 & 15 & 14 & 87,28 & 0,8 & 1 & 36 & 100,1 & 0,63 & 0,731 \\
\hline Sillillica & SL & I & $\mathrm{Iq}$ & Pic & 3 & 33 & 3 & 174,19 & 0,9 & 1,4 & 3 & 174,2 & 0,88 & 1,38 \\
\hline Sierra Overa & SO & II & An & Tal & 2 & 3 & 0 & -100 & -100 & -100 & 0 & -100 & -100 & -100 \\
\hline San Pedro Conchi & SP & II & Lo & $\mathrm{Cal}$ & 3 & 47 & 32 & 59,08 & 0,7 & 0,8 & 43 & 59,71 & 0,76 & 0,86 \\
\hline Cachinal de la Sierra & SR & II & An & Tal & 3 & 1 & 0 & -100 & -100 & -100 & 0 & -100 & -100 & -100 \\
\hline Río Cancosa en Tambo & $\mathrm{TB}$ & I & $\mathrm{Iq}$ & PAl & 3 & 4 & 2 & -100 & -100 & -100 & 2 & -100 & -100 & -100 \\
\hline Toconao Retén & $\mathrm{TC}$ & II & Lo & SPA & 3 & 17 & 16 & 41,11 & 0,7 & 0,4 & 40 & 36,83 & 0,68 & 0,95 \\
\hline Toconao Experimental & $\mathrm{TE}$ & II & Lo & SPA & 3 & 35 & 29 & 34,29 & 0,9 & 0,8 & 40 & 34,73 & 0,91 & 0,72 \\
\hline Tignamar & TI & XV & $\mathrm{Pa}$ & Put & 2 & 48 & 39 & 123,69 & 0,8 & 2,4 & 48 & 130,9 & 0,76 & 1,87 \\
\hline Talabre & $\mathrm{TL}$ & II & Lo & SPA & 3 & 21 & 16 & 66,76 & 0,9 & 0,9 & 40 & 72,66 & 0,63 & 0,51 \\
\hline Toconce & $\mathrm{TN}$ & II & Lo & $\mathrm{Cal}$ & 3 & 44 & 40 & 95,58 & 0,8 & 1,3 & 44 & 98,27 & 0,84 & 1,27 \\
\hline
\end{tabular}




\begin{tabular}{|c|c|c|c|c|c|c|c|c|c|c|c|c|c|c|}
\hline Estación & Id & $\mathbf{R g}$ & Pr & $\mathrm{Cmn}$ & $\mathrm{T}$ & A & Ac & $\bar{x}$ & $\mathrm{CV}$ & CS & Ac' & $\bar{x}$ & CV' & $\mathrm{CS}$ \\
\hline Tocopilla & $\mathrm{TP}$ & II & To & Tpl & 1 & 24 & 20 & 0,84 & 4,3 & 4,5 & 90 & 2,34 & 1,34 & 2,3 \\
\hline Turi & TR & II & Lo & $\mathrm{Cal}$ & 3 & 13 & 11 & 37,2 & 0,9 & 0,8 & 38 & 39,25 & 0,72 & 0,81 \\
\hline Tranque Sloman & $\mathrm{TS}$ & II & To & MEl & 2 & 9 & 8 & 0 & -0 & -100 & 8 & 0 & -100 & -100 \\
\hline Taltal & $\mathrm{TT}$ & II & An & Tal & 1 & 45 & 0 & -100 & -100 & -100 & 46 & 12,14 & 1,17 & 1,76 \\
\hline Q. Camiña $3 \mathrm{~km}$ a Tarcavire & TV & I & Iq & Cañ & 2 & 10 & 7 & 83,04 & 0,6 & 0,5 & 7 & 83,04 & 0,64 & 0,47 \\
\hline Universidad Antofagasta & UA & II & An & Ant & 1 & 47 & 9 & 1,88 & 1,5 & 1,7 & 9 & 1,88 & 1,48 & 1,67 \\
\hline Ujina & UJ & I & Iq & Pic & 3 & 42 & 26 & 169,53 & 0,7 & 1,3 & 34 & 169,8 & 0,61 & 1,23 \\
\hline U. del Norte & UN & XV & $\mathrm{Ar}$ & $\mathrm{Ar}$ & 1 & 10 & 2 & -100 & -100 & -100 & 2 & -100 & -100 & -100 \\
\hline Villa Industrial Tacora & $\mathrm{VI}$ & XV & $\mathrm{Pa}$ & GLg & 3 & 41 & 34 & 296,15 & 0,6 & 0,6 & 42 & 314,3 & 0,5 & 0,29 \\
\hline Vaquillas & VQ & II & An & Tal & 3 & 2 & 0 & -100 & -100 & -100 & 0 & -100 & -100 & -100 \\
\hline Visviri & VR & $\mathrm{XV}$ & $\mathrm{Pa}$ & GLg & 3 & 48 & 39 & 277,69 & 0,5 & 0,8 & 42 & 282,3 & 0,5 & 0,71 \\
\hline Chungará Ajata & $\mathrm{XA}$ & $\mathrm{XV}$ & $\mathrm{Pa}$ & Put & 3 & 33 & 27 & 366,94 & 0,4 & 0,9 & 53 & 363,2 & 0,36 & 0,38 \\
\hline Conchi embalse & $\mathrm{XB}$ & II & Lo & $\mathrm{Cal}$ & 3 & 49 & 36 & 20,35 & 0,9 & 1,6 & 42 & 20,42 & 0,88 & 1,52 \\
\hline Chaca & $\mathrm{XC}$ & $\mathrm{XV}$ & $\mathrm{Ar}$ & $\mathrm{Ar}$ & 2 & 16 & 14 & 0 & -100 & -100 & 14 & 0 & -100 & -100 \\
\hline Chocuyo ex Endesa & $\mathrm{XE}$ & $\mathrm{XV}$ & $\mathrm{Pa}$ & Put & 3 & 7 & 3 & 307,33 & 0,1 & $-1,7$ & 3 & 307,3 & 0,1 & $-1,72$ \\
\hline Chungará Guardería & $\mathrm{XG}$ & XV & $\mathrm{Pa}$ & Put & 3 & 4 & 1 & -100 & -100 & -100 & 1 & -100 & -100 & -100 \\
\hline Chiapa & XI & I & $\mathrm{Iq}$ & Cañ & 2 & 28 & 22 & 29,74 & 1,4 & 2,7 & 36 & 29,87 & 1,22 & 2,76 \\
\hline Chilcaya & $\mathrm{XL}$ & $\mathrm{XV}$ & $\mathrm{Pa}$ & Put & 3 & 45 & 29 & 270,89 & 0,6 & 1,2 & 48 & 293,2 & 0,47 & 0,89 \\
\hline Conchi muro embalse & $\mathrm{XN}$ & II & Lo & $\mathrm{Cal}$ & 3 & 14 & 11 & 20,77 & 0,7 & 0,2 & 42 & 20,62 & 0,64 & 0,91 \\
\hline Portezuelo Chapiquiña & $\mathrm{XN}$ & XV & $\mathrm{Pa}$ & Put & 2 & 4 & 0 & -100 & -100 & -100 & 4 & 0 & -100 & -100 \\
\hline Río Camarones Chilpe & $\mathrm{XP}$ & XV & $\mathrm{Ar}$ & Cam & 2 & 11 & 10 & 14,67 & 1 & 0,7 & 41 & 15,8 & 0,79 & 0,87 \\
\hline Chungará Retén & $\mathrm{XR}$ & $\mathrm{XV}$ & $\mathrm{Pa}$ & Put & 3 & 54 & 32 & 314,89 & 0,4 & 0,7 & 53 & 311,7 & 0,38 & 0,65 \\
\hline Chocuyo Retén & $\mathrm{XY}$ & $\mathrm{XV}$ & $\mathrm{Pa}$ & Put & 3 & 56 & 42 & 344,4 & 0,3 & 0,4 & 55 & 347,3 & 0,35 & 0,28 \\
\hline Chuzmiza & $\mathrm{XZ}$ & I & $\mathrm{Iq}$ & Cañ & 2 & 28 & 19 & 132,02 & 1 & 1,8 & 36 & 124,6 & 0,97 & 1,82 \\
\hline Coya Sur & YS & II & To & MEl & 2 & 18 & 15 & 0,66 & 2,5 & 2,4 & 36 & 0,85 & 1,54 & 1,95 \\
\hline
\end{tabular}

Fuente: Elaboración propia sobre la base de las estaciones DGA.

igualmente en oasis donde se incluyen 41 estaciones de más de 365 m hasta 2450; y 3) las restantes 79 en el altiplano. La separación de los tres ámbitos se ha efectuado a tenor de los cortes que se observan en el continuиm de la gráfica de estaciones y altitud (Gráfico 1), de ahí que sea prescindible la lectura de las siglas que identifican a cada estación, que, a su vez, están reseñadas en la Tabla 1 .

La localización de las estaciones se ha realizado mediante la cartografía del mapa oficial de carreteras de Chile; Sistema de Información Geográfica y de las coordenadas facilitadas por DGA y GISS de la NASA. Lamentamos tener que decir que la localización precisa es un inconveniente más a la laxa malla de la red, lo que incrementa otros valladares como la reiterada interrupción de las series, amén de la apertura y cierre de estaciones.

Hay concentración de las lecturas en los lugares habitados. Sorprende que en las inmediaciones del Huasco se encuentren Altos del Huasco, Salar de Huasco y Sillillica, aunque se sucedan en la toma de registros; otro tanto ocurre en Canosa y Río Canosa en Tambo, también estaciones sucesivas; lo más notable es la proximidad de las estaciones de los lagos Chungará y Cotacotani: Chungará Ajata, Chungará Guardería y Chungará Retén; Parinacota Ex Endesa, Parinacota Conaf e Isla Blanca; Cotacotani y Río Desaguadero en Cotacotani. También merecen 
Gráfico 1. Altitud de las estaciones meteorológicas

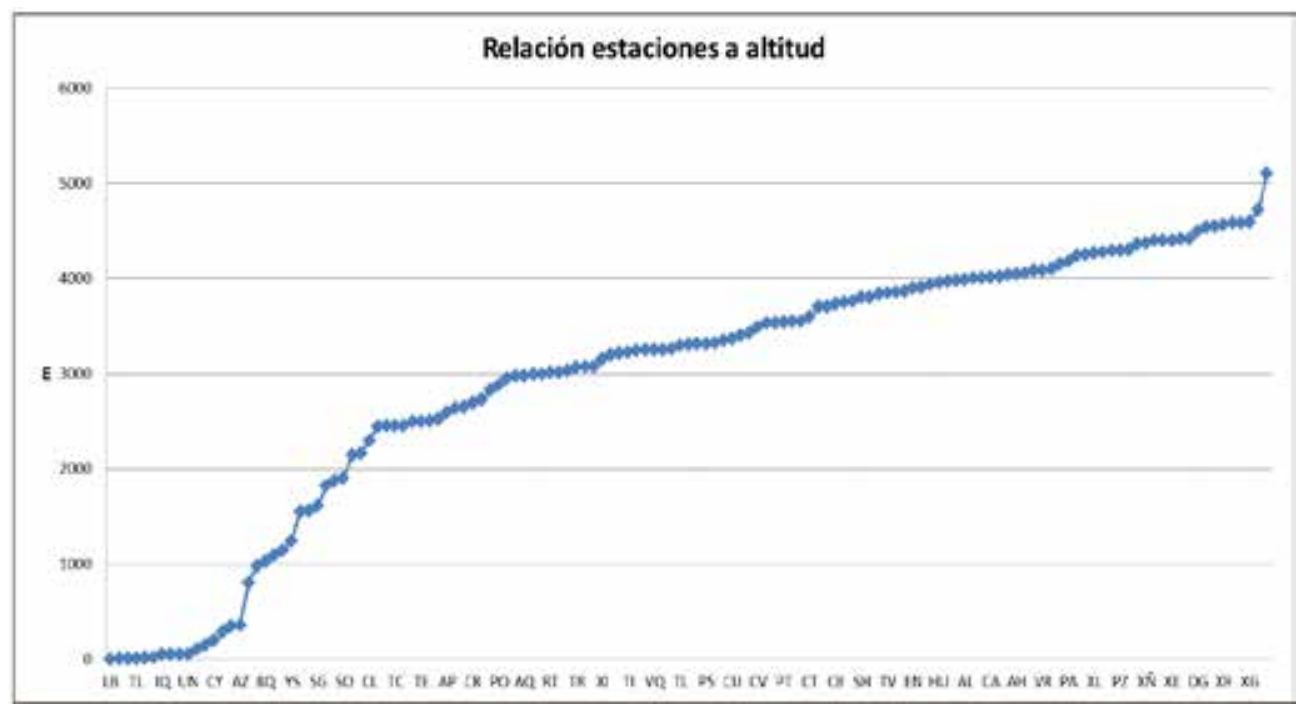

mención Chocuyo Ex Endesa y Chocuyo Retén, así como la vecindad de Putre, Las Cuevas Conaf y Pacollo.

Es acertado que el título del proyecto no aspire a un estudio de cambio climático, al no poderse trabajar una comparativa de al menos 3 períodos de 30 años, los mínimos necesarios para ello. Para conocer los principales estadísticos de las series originales véase la Tabla 1. Es importante destacar las grandes diferencias en el total de precipitación (máximo = Caquena con $413 \mathrm{~mm}$; mínimo en Chaca, Tranque Sloman con 0), en los coeficientes de variación $($ máx $=\mathrm{TP}, 4,25 ;$ mín $=$ XE, 0,1 y valores muy semejantes a los obtenidos por Sarricolea y Romero, (2015, pág. 175) para las estaciones altiplánicas), y de sesgo (Iquique con 8,1 frente a Caquena con $0,1)$. El incremento del sesgo, al igual que el CV, denota tanto mayor aridez.

Se ha procedido al rellenado de las lagunas mediante el programa Chac (Cedex, 2013), disponible de modo gratuito en $h t t p: / / h e r c u l e s . c e d e x . e s /$ chac/, que sigue un modelo bivariado de regresión con estacionarización previa mensual de las series de datos, bajo ciertas condiciones impuestas por el usuario, entre otras, las agrupaciones de estaciones, permitiendo a una misma estación estar presente en varios grupos (afinidad geográfica y estadística). Se seleccionan las estaciones que poseen más de cinco datos en cada uno de los doce meses del período seleccionado. Obsérvese que en la Tabla 1 los valores de la media de las series originales y completadas apenas difieren, como tampoco los restantes indicadores, salvo excepciones como AO, AS, BQ, FB, QU, RS, SA, TC, TL, TP, VI, XA, y XN, debido, básicamente, al aumento en el número de valores estimados y a la creciente aridez. Al menos desde esta óptica el proceso de rellenado logra sus objetivos sin distorsionar las series. Por ello, en otros análisis de áreas próximas (Sanz Donaire, 2010) se había optado por completar excepcionalmente algún valor mensual faltante con la media de toda la serie de ese mes, de rápida inserción, aunque fuera un proceder no exento de críticas. Se ha dado sombreado de fondo a las columnas de los datos rellenos cuando se ha prolongado la serie inicial.

Con el ánimo de descubrir las posibles reiteraciones de comportamiento de los valores pluviométricos se ha actuado en tres frentes: realización de gráficos de desviaciones acumuladas para explicitar períodos húmedos y secos, contraste de hipótesis respecto de una serie aleatoria, y dibujo e interpretación de periodogramas.

\section{Los gráficos de desviaciones acumuladas}

Los gráficos de desviaciones acumuladas, trabajo sencillo y provechoso, ponen de manifiesto el comportamiento más o menos repetitivo (periódico no se emplea con el mismo significado que cíclico, aunque no exista diferencia apreciable 
Mapa 1. Mapa de la ubicación de las estaciones pluviométicas disponibles.

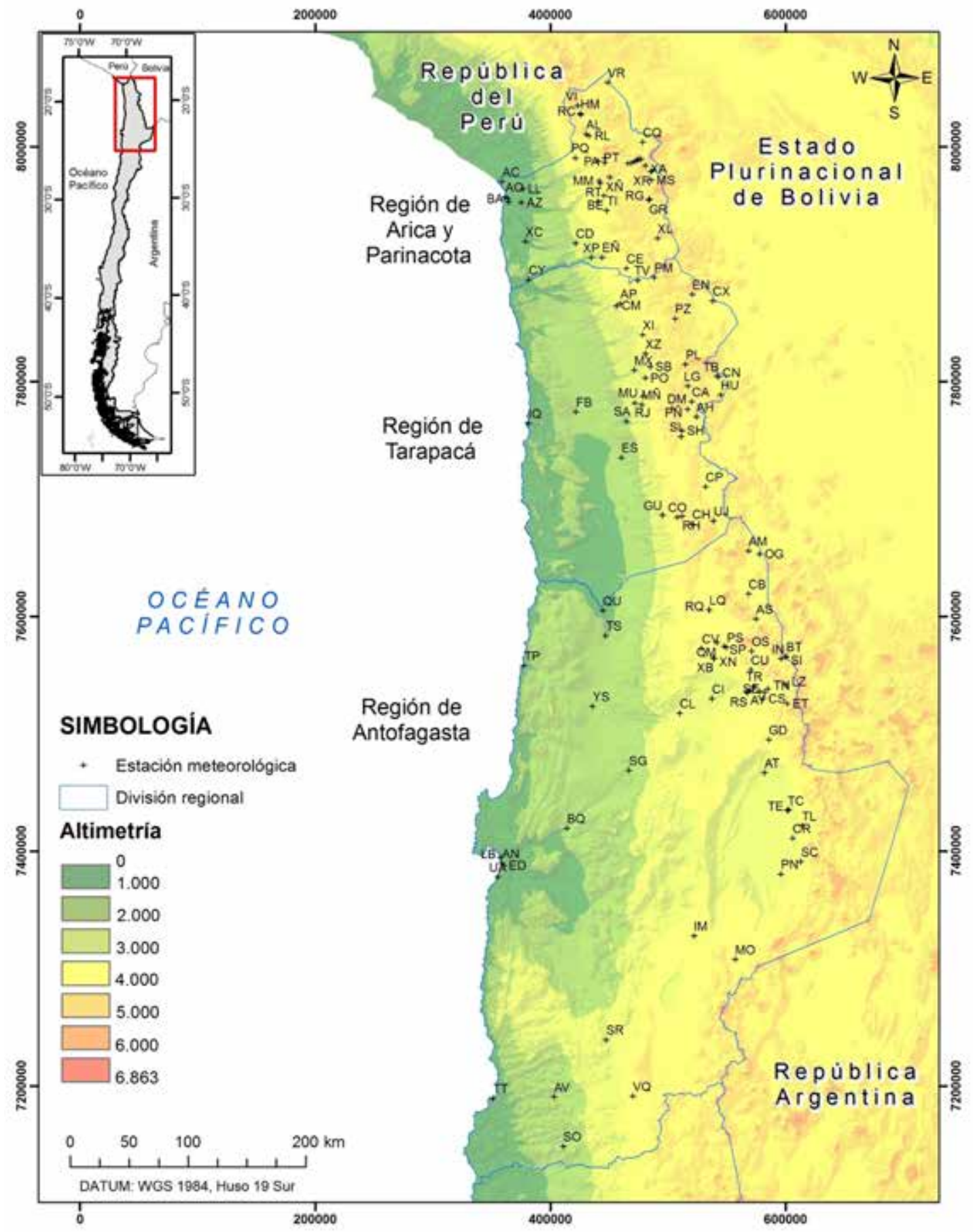

Fuente: Elaboración propia. 
en la etimología de las dos palabras -la primera se refiere al camino alrededor [se supone de un círculo o de una esfera], la segunda a la rueda [evidentemente redonda] en las precipitaciones-). Como en su realización se precisa series mensuales continuadas de datos, solo se ha realizado el gráfico en aquellos casos en que este era significativo, despreciando los observatorios de grandes lagunas, así como los que disponen de una serie demasiado corta, sin pauta de comportamiento reconocible (véase Tabla 1): AJ, AM, AP, AQ, BT, DG, EC, ED, ES, IM, LB, LC, MM, MO, MS, PQ, PZ, RC, RH, SB, SH, SO, SR, TB, TS, VQ y XG. Existen algunos problemas inherentes a la construcción del gráfico: cada año que se agrega cambia el valor de la media, la referencia, luego la consiguiente representación. Pero este hecho se minimiza si las series son largas, algo bastante infrecuente en el área de estudio. El gráfico termina de manera inequívoca en 0 , y este puede no coincidir con el tiempo final del estudio (diciembre de 2015). Se suscita la cuestión de las series que terminan en diferentes momentos, pues presentan dificultad de comparación, por falta de acople. En algunos casos se precisaría sumar a los valores iniciales un "zócalo", de tal modo que se ajustasen mejor los datos de dos estaciones con los mismos altibajos, aunque a diferentes alturas.

Los gráficos de desviaciones se han comparado entre sí mediante los coeficientes de correlación gracias al programa estadístico Statgraphics@ en versión Centurión XVII. Como ejemplo se aportan las comparaciones entre algunas estaciones atacameñas en la Tabla 2.

Tabla 2. Matriz de correlaciones de algunas series pluviométricas.*

\begin{tabular}{|c|c|c|c|c|c|c|c|}
\hline \multicolumn{2}{|l|}{ Calama } & \multirow[b]{4}{*}{ Chiuchiu } & \multirow[b]{7}{*}{ Ayquina } & \multirow[b]{10}{*}{ Caspana } & & & \\
\hline Chiuchiu & 0,0840 & & & & & & \\
\hline & (41) & & & & & & \\
\hline & 0,6017 & & & & & & \\
\hline \multirow[t]{3}{*}{ Ayquina } & 0,8102 & 0,0882 & & & & & \\
\hline & (48) & (41) & & & & & \\
\hline & 0,0000 & 0,5834 & & & & & \\
\hline \multirow[t]{3}{*}{ Caspana } & 0,4958 & $-0,0824$ & 0,9114 & & & & \\
\hline & (38) & (34) & (38) & & & & \\
\hline & 0,0015 & 0,6432 & 0,0000 & & & & \\
\hline \multirow[t]{3}{*}{ El Tatio } & $-0,0069$ & 0,7614 & 0,2126 & 0,2455 & & & \\
\hline & (38) & (38) & (38) & (31) & & & \\
\hline & 0,9673 & 0,0000 & 0,2001 & 0,1831 & El Tatio & & \\
\hline \multirow[t]{3}{*}{ Linzor } & 0,6481 & $-0,0526$ & 0,8988 & 0,8192 & 0,1591 & & \\
\hline & (42) & (41) & (42) & (35) & (38) & & \\
\hline & $\mathbf{0 , 0 0 0 0}$ & 0,7439 & 0,0000 & 0,0000 & 0,3402 & Linzor & \\
\hline \multirow[t]{3}{*}{ Parshall n2 } & 0,6292 & 0,4333 & 0,7955 & 0,5407 & 0,5789 & 0,5995 & \\
\hline & (43) & (38) & (43) & (38) & (35) & (39) & \\
\hline & 0,0000 & 0,0066 & 0,0000 & 0,0005 & 0,0003 & 0,0001 & $\begin{array}{c}\text { Parshall } \\
\text { n2 } \\
\end{array}$ \\
\hline \multirow[t]{3}{*}{ Ojos San Pedro } & $-0,0464$ & 0,7416 & $-0,1001$ & $-0,3722$ & 0,6630 & $-0,2201$ & 0,1119 \\
\hline & (46) & (41) & (46) & (38) & (38) & (42) & (43) \\
\hline & 0,7595 & 0,0000 & 0,5080 & 0,0214 & 0,0000 & 0,1612 & 0,4750 \\
\hline
\end{tabular}

* Se consignan 3 valores en cada cruce de dos estaciones: arriba, el coeficiente de correlación; en el centro, entre paréntesis, el número de parejas de valores con los que se elabora la tabla; y, debajo, el valor $p$, a efectos de conocer la significación estadística, de tal modo que las cifras $<0,05$ (en rojo) son significativas al $95 \%$. 
Es llamativo que el máximo ajuste entre dos estaciones sea entre Parinacota ex-Endesa e Isla Blanca: 0,9957, así como entre Chungará Ajata e Isla Blanca $(0,9562)$, si bien para 7 y 6 parejas de valores únicamente, aunque sea significativo al $95 \%$ (ver Gráfico 2). Este hecho plantea la importancia que tiene la longitud de las series coincidentes, cuyo peso es máximo en el resultado final. El ejemplo sería digno de aparecer en el libro How to Lie with Statistics.

No existe espacio para exponer todos y cada uno de los análisis bivariados expresados por medio de los coeficientes de correlación. La pauta general es que hay estaciones próximas con correlaciones altas, mientras que también las hay para estaciones bastante alejadas geográficamente. En definitiva: la proximidad espacial no implica necesariamente proximidad estadística. Ello pone de manifiesto un cierto grado de aleatoriedad en las series, o dicho de otro modo, una cantidad de factores intervinientes tan grande que la ponderación particular en cada caso es variable y, por esta razón, resulta de gran dificultad vislumbrar las pautas de conducta, lo que casi imposibilita una predicción o pronóstico.

Se incluye, a modo de ejemplo, uno de los gráficos realizados de los tipos de desviaciones acumuladas más repetidos (Gráfico 3).

Caspana y Ayquina arrojan un coeficiente de correlación muy alto $(>0,92)$ para un total de 38 parejas de datos. Ello también se muestra en los gráficos. Por otra parte, las estaciones de Iquique (datos de la DGA) e Iquique mezcla (de la serie construida con otras fuentes) apenas se asemejan: coeficiente de correlación de -0,0868 para 31 pares de datos comunes. Prácticamente constituye el extremo opuesto, la máxima disimetría.

La variedad de comportamientos es grande, pero esconden ritmos evidentes, que merecen un estudio pormenorizado, distinto, en su concepción, de las tradicionales tendencias. Estas, a nuestro entender, son demasiado burdas como para describir la naturaleza de los cambios. Una simple recta con mayor o menor pendiente de subida o bajada, pero siempre constante, es insuficiente para manifestar la variabilidad que observamos. Tampoco parecen amoldarse las gráficas a modelos linealizables (exponenciales, logarítmicas, potenciales), ni a curvas en "ese" u otras.

Renunciamos a publicar las gráficas de las desviaciones acumuladas de las estaciones rellenas, por cuanto que los valores son estimados, que no tan representativos de la realidad que se sabe ocurrió (auténticos "datos"1). Pensamos que, inicialmente, la realidad no debe ser suplantada por la teoría, aunque ello nos permita afirmar muchas más conclusiones que las desprendidas de los datos. Creemos que ello es admitir como verdaderos tantos supuestos que lo que obtenemos no deja de ser sino aquello que

Gráfico 2. Análisis bivariados expresados mediante coeficiente de correlación.,

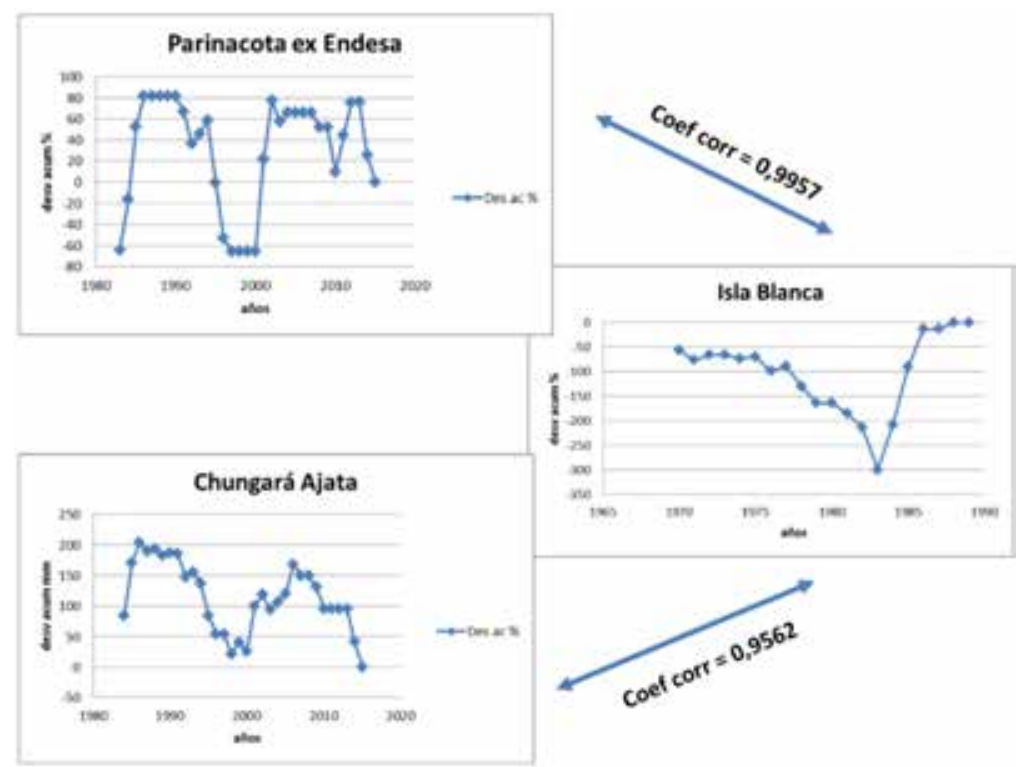

*Nótese que las escalas no son las mismas. 
Gráfico 3. Gráficos de desviaciones acumuladas de algunos observatorios.

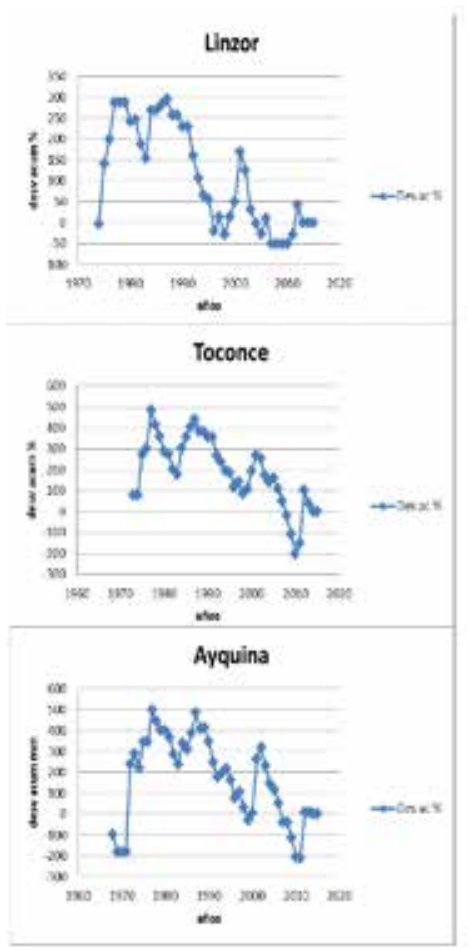

nosotros hemos fabricado, por lo que nos habríamos hecho trampa en el trabajo. Solo a título orientativo reproducimos una estación rellena en la que se ha operado como en las restantes con desviación acumulada: Turi (Gráfico 4). En este caso se ha mantenido la misma escala y serie temporal, para que las variaciones sean más fáciles de reconocer. Los estadísticos muy semejantes se recogen en la Tabla 1. El año 1989 tenía en origen 4 meses faltantes, que implican una "meseta" en la gráfica, mientras que en los valores rellenos se eleva a la punta máxima de los valores completados acumulados. El rellenado se ha llevado a la práctica con las muchas estaciones circundantes en las que sí hay datos (Cupo, Ojos de San Pedro, Linzor, Caspana, Ayquina, Ascotán, Inacaliri, Salado embalse, etc.)

\section{Estudio de periodicidades}

\section{La preparación de los periodogramas}

Por lo general se ha trabajado de dos maneras: a) con los datos "crudos"; y b) con relleno de los años faltantes, según grupos definidos sobre la base

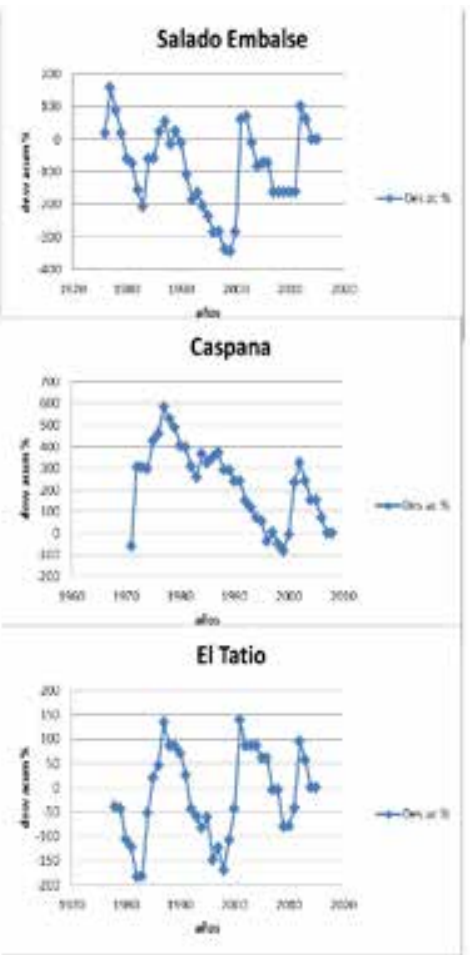

de la proximidad estadística (valor de la media, coeficiente de variación y sesgo), matizados por la proximidad geográfica, relleno efectuado merced a la aplicación del algoritmo correspondiente del programa Chac.

Sin embargo, un valladar que se suscita con los rellenos automáticos de los datos faltantes en el programa Chac es que los valores estimados varían según los exponentes de priorización que hayamos introducido en el proceso.

A modo de ejemplo, véase en la Tabla 3 la diferencia en los valores estimados finales, con dos exponentes distintos, uno de ellos bien extremo $(0,1)$ : el ensayo se ha realizado para la estación, que ya no está vigente, de Arica Aeródromo de El Buitre, teniendo como datos de referencia las estaciones inmediatas de Arica Chacalluta (el aeropuerto, la serie más completa), Arica Oficina (de la DGA, también muy completa), y Azapa. De sobra es conocido que, en lugares áridos, y no cabe duda de que las estaciones de Arica lo son, la variabilidad espacial y temporal de las precipitaciones es máxima.

Nótese que, para los últimos 4 años, la estación del Aeródromo no dispone de ningún dato mensual. 
Gráfico 4. Comparativa de serie original y rellena.
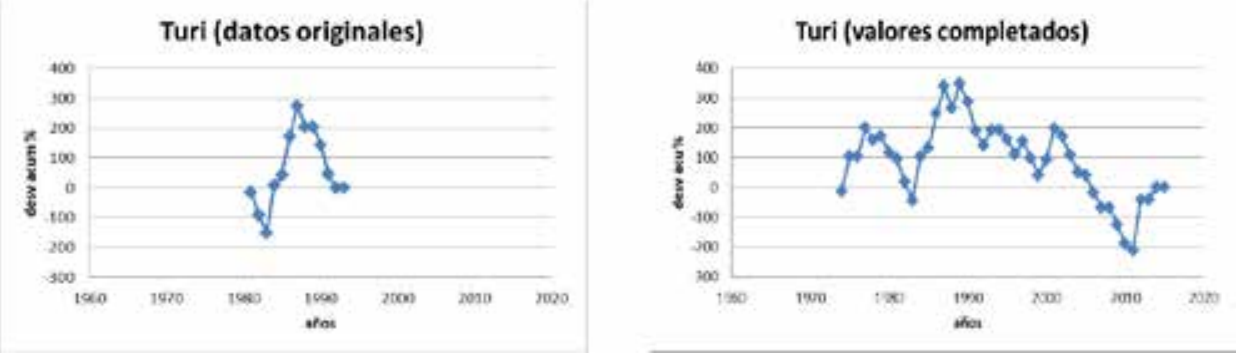

Tabla 3. Cálculos según diferentes exponentes de priorización.

\begin{tabular}{|c|c|c|c|c|c|c|c|c|c|}
\hline Año & $\begin{array}{l}\text { Valor } \\
\text { real }\end{array}$ & $\begin{array}{c}\text { Exponente } \\
\mathbf{0 , 4}\end{array}$ & $\begin{array}{c}\text { Exponente } \\
0,1\end{array}$ & $\begin{array}{c}\text { Diferencia } \\
\%\end{array}$ & Año & $\begin{array}{l}\text { Valor } \\
\text { real }\end{array}$ & $\begin{array}{c}\text { Exponente } \\
0,4\end{array}$ & $\begin{array}{c}\text { Exponente } \\
0,1\end{array}$ & $\begin{array}{c}\text { Diferencia } \\
\%\end{array}$ \\
\hline 1973 & faltante & 1 & 1 & 0 & 1982 & faltante & 1 & 1,5 & 50 \\
\hline 1974 & faltante & 1,2 & 1,4 & 20 & 1983 & faltante & 0,8 & 0,7 & -10 \\
\hline 1975 & faltante & 3 & 1,8 & -120 & 1984 & faltante & 0,9 & 1 & 10 \\
\hline 1976 & faltante & 1,1 & 1,8 & 70 & 1985 & faltante & 0,4 & 0,8 & 40 \\
\hline 1977 & faltante & 1,4 & 1,7 & 30 & 2012 & faltante & 2,8 & 1,4 & -140 \\
\hline 1978 & faltante & 2,8 & 0,7 & -210 & 2013 & faltante & 0,7 & 1,3 & 60 \\
\hline 1979 & faltante & 2,1 & 1,2 & -90 & 2014 & faltante & 2,4 & 1 & -140 \\
\hline 1980 & faltante & 1,3 & 0,6 & -70 & 2015 & faltante & 0,7 & 1,1 & 40 \\
\hline 1981 & faltante & 1,6 & 0,9 & -70 & & & & & \\
\hline
\end{tabular}

Tabla 4. Datos crudos y completados de períodos repetidos.

\begin{tabular}{l|cccc|cccc}
\hline \multirow{2}{*}{ Estación Orden } & \multicolumn{4}{|c|}{ Datos Crudos Statgraphics } & \multicolumn{4}{c}{ Datos Completados $(\mathbf{E = 0 , 4 ; ~} \mathbf{U = 0 , 1})$} \\
\cline { 2 - 10 } & $1^{\mathbf{o}}$ & $2^{\mathbf{o}}$ & $3^{\mathbf{o}}$ & $4^{\circ}$ & $1^{\mathbf{o}}$ & $2^{\mathbf{o}}$ & $3^{\mathbf{o}}$ & $4^{\mathbf{0}}$ \\
\hline Arica Chacalluta & 10,5 & 5,6 & $(84)$ & & 2,32 & 14,33 & 7,16 & 2,77 \\
\hline Arica Oficina & 5,12 & 2,27 & 8,2 & $(41)$ & 7,83 & 5,22 & 2,23 & \\
\hline Azapa & 2,76 & 4,7 & 5,87 & & 2,71 & 4,7 & 5,87 & 7,83 \\
\hline El Buitre Aeródromo & 8,66 & 2,16 & & & 2,13 & $(47)$ & 7,11 & 2,76 \\
\hline
\end{tabular}

No obstante, no existe una pauta uniforme de relleno, pues las diferencias de los datos estimados van desde un déficit del 210 y 140\% (en dos ocasiones), hasta un superávit del $70 \%$.

Debido a que para cada exponente de priorización el cálculo se realiza de un modo distinto es difícil decantarse por uno u otro, al haber desaparecido todo elemento que nos permita argumentar en un determinado sentido. Porque la primera vez que se alcanza a completar la serie con 90 años válidos para Chacalluta y 45 valores para el resto de las estaciones es con un exponente de priorización de 0,4 , umbral $=0,1$, tomamos esta como la completada más idónea, en la que realizamos los ensayos de ritmicidad. En la aplicación a todas las estaciones se ha utilizado 0,7 y 0,1 , respectivamente.

Básicamente los comentarios que suscita este relleno son los siguientes:

Los periodogramas de Arica Chacalluta y Arica Oficina (Tabla 4) arrojan el mismo patrón: fuerte influencia de repeticiones cada 5 años, que, en el caso de la serie de 84 años, también deviene - ¿por 
repetición? - decadal. En el caso de Arica Oficina hay un segundo máximo en 8,2 años, que, tal vez, pudiera por de manifiesto esta misma realidad.

En la Tabla 4 se han puesto ordenados jerárquicamente los períodos que se repiten en los periodogramas a tenor del cálculo efectuado por Statgraphics, tanto de las series "crudas" como de los datos completados mediante el programa Chac para $\mathrm{E}=$ exponente de priorización y $\mathrm{U}=$ umbral de priorización. Los valores entre paréntesis se pueden explicar por la longitud de la serie, por lo que carecerían de auténtico sentido periódico.

Destacadas en sombra aparecen las coincidencias entre las dos series, coincidencias que son bastante notables en los datos de todas las estaciones salvo en la más longeva, Chacalluta. Puede ocurrir que el completado de la serie cambie el orden de importancia de los ciclos, aunque por lo general se mantienen. Téngase en cuenta que las series de Arica Oficina y Azapa eran originalmente de 39 datos y han pasado a 45 al completar. El Buitre partiendo de 25 años ha logrado repletar los mismos 45 que sus compañeros: este relleno más completo ha debido influir, sin duda, en una detección de ciclos parecidos a las estaciones vecinas.

A los valores así obtenidos se ha denominado "series completadas". Como se verá, todavía el tratamiento mediante el programa estadístico Statgraphics@ Centurión en su versión XVII ha añadido más valores a los ya completados, con los inconvenientes que se explican a continuación. Para los periodogramas este programa estima los valores faltantes, de tal modo que interpola entre los valores anteriores y posteriores aplicando una simple proporcionalidad.

A estas consideraciones debemos agregar todavía la propia debilidad del sistema en detectar, para los periodogramas, una señal fuerte en la mitad del tiempo en el que se ha recogido información. Y, de modo semejante, en las sucesivas mitades (cuartos, octavos, dieciseisavos, treintaidosavos, etc.) del conjunto de datos, porque es así como funciona el algoritmo para denotar la periodicidad en la serie.

Por otro lado, sí se observan coincidencias en las diferentes estaciones, ya que los períodos parecen agruparse en torno a $5(5,87 ; 5,6 ; 5,22 ; 5,12$ y 4,7$)$, su múltiplo 10,5 y su divisor $2,5(2,77 ; 2,76 ; 2,71$; $2,32 ; 2,27 ; 2,16$ y 2,13$)$. Finalmente quedarían los valores en torno a $7,8(8,66 ; 8,2 ; 7,83,7,16$ y 7,11$)$ -para los que no se descarta una suma de $5+2,5$ ) y su múltiplo $14,33(¿ 10+5$ ?). Como se sabe la presencia de múltiplos y divisores es una condición propia de la naturaleza del análisis. Lo que de momento resulta de una mayor dificultad es achacar los períodos detectados a procesos conocidos (El Niño, variación decadal, etc.).

\section{Tests de aleatoriedad pasados en las estaciones norchilenas}

Si existen períodos repetidos, ello parece arrinconar la posibilidad de un comportamiento aleatorio, que, no obstante, se ha querido probar. Los tests de aleatoriedad también se basan en los valores rellenados por interpolación según se ha comentado en los periodogramas. Si los datos faltantes se disponen todos en una única laguna larga, los resultados del relleno pueden llegar a ser absurdos. La situación más favorable es aquella en la que se rellenan faltantes únicos entre dos datos registrados, como en el caso expuesto de Parinacota ex-Endesa. Esta aclaración ya se había comentado en Sanz Donaire (2010). Para corroborar esta afirmación, véase graficada la serie estimada de la estación de Guallatire (Gráfico 6), que tiene dos momentos de registro separados por una laguna larga, cuyo relleno arroja valores negativos de precipitación en bastantes años, una realidad imposible, lo que cuestiona la pertinencia del tipo de análisis con estos valores.

Los enunciados de las tres pruebas son los mismos para los dos análisis utilizados, con datos originales y completados.

Test 1: Corridas arriba o abajo de la mediana; significación al 95\%; Test 2: Corridas arriba y abajo; significación al 95\%; Test 3: Prueba Box-Pierce (autocorrelación); al 95\%.

Si una estación no pasa alguno de los tres tests, a causa de que cada uno de estos es sensible a un tipo diferente de patrón de aleatoriedad, implica que el resultado pudiera no ser aleatorio, al $95 \%$ de probabilidad. Recuérdese que ello significa que, aún y así, todavía cabe la posibilidad -con una probabilidad muy baja (del 5\%) - de que sea cierto lo contrario de lo expuesto.

De los tests precedentes se debe comentar: 1) cuando el resultado de los tres tests es negativo se ha destacado el cuadro con un sombreado suave; 2) solo se consignan las estaciones cuyos análisis, al rellenar el programa, tienen sentido, excluyendo los modelos Guallatire (videat supra); 3) por lo general, las series rellenas mediante el programa Chac ofrecen resultados más favorables a la aleatoriedad: 72,9\% 
Gráfico 6. Gráfica de precipitaciones calculadas para Guallatire.

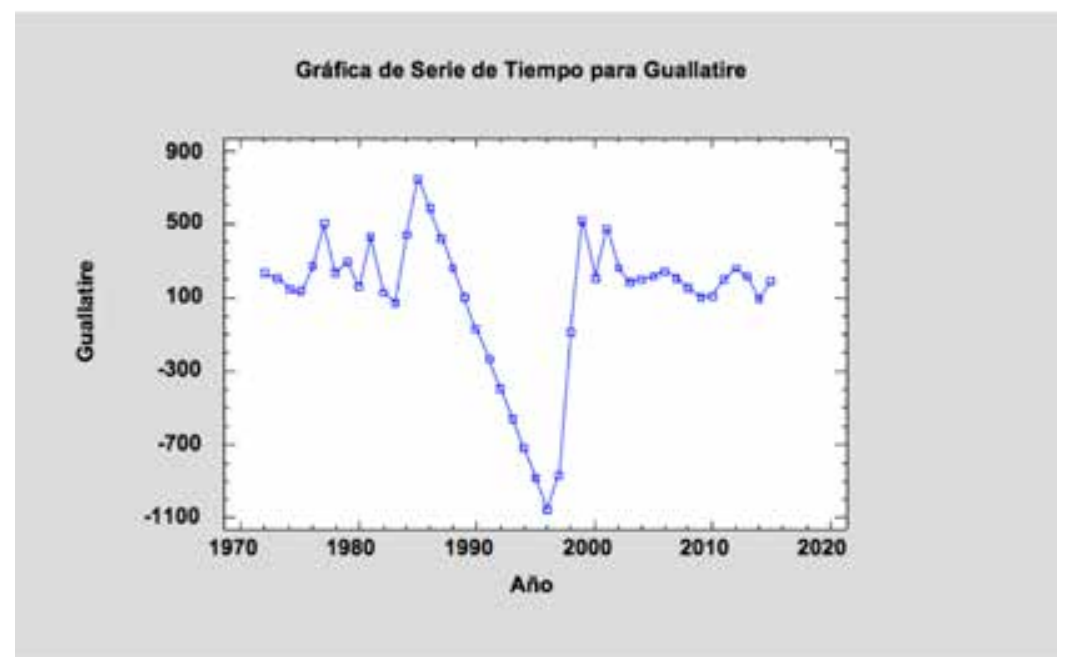

frente a $45,5 \%$. Este aumento debería estar ligado a una mayor longitud de la serie, ya que la brevedad puede inducir a falsos negativos; 4) espacialmente los noes suelen presentarse aislados entre los valores positivos, aunque es posible señalar los aglomerados de Arica (AC, AO, BA, AZ), de Cotacotani (CC, $\mathrm{XA}, \mathrm{XR}$ ), la franja limítrofe con Perú (PQ, AL, VI), el ámbito Taltal-Aguas Verdes, o la amplia área entre Baquedano, Calama, Quillagua y Tocopilla. 5) Llama la atención que, de las estaciones de la sierra al Este del salar de Atacama, solo Socaire sea negativa. ¿Una prueba de la originalidad que ya refleja su nombre? 6) En la distribución territorial de los noes en los datos completados se disuelven los núcleos antes mencionados, que pasan a dejar apenas una estación testimonial (caso de TP, QU y SG; o de XR en el altiplano parinacoteño, salvo para el entorno de Arica (AO, AC, AZ, BA). Emerge un núcleo fronterizo entre Ollagüe y Ujina, o entre Lagunillas y Camiña.

Tal vez el análisis realizado en busca de comportamientos periódicos frente a los aleatorios no haya sido demasiado expresivo, por lo que se hace hincapié en las repeticiones ordenadas, las periodicidades.

\section{El periodograma}

Se trata de un gráfico que debe poner de manifiesto los ritmos que se repiten en el tiempo. Al aplicarlo a los datos pluviométricos anuales ofrece las oscilaciones de este meteoro en la Tabla 5. En esta se puede observar los valores de los períodos detectados en orden alfabético de las siglas. Las estaciones faltantes son aquellas en las que no se ha podido realizar el análisis por las causas aducidas. En ciertos casos los períodos al rellenar se mantienen en el mismo orden (como en TR, ET), si bien en otros (CV, VR, PO, TE, PT, XB) cambia la importancia relativa. Solo muy raramente se observa un traslado de las cifras (SG). Debe destacarse que es frecuente que, dada la propia construcción del gráfico, aparezca reforzado el valor de la longitud de la serie (n), o bien su inmediato divisor (n/2). Por ello se ha querido restar importancia a estos casos, oscureciendo ligeramente la celda en la que aparecen.

Existen determinados valores que se repiten con frecuencia: son los de 22, 11-10, 5, 3 y 2 años, si bien con bastante irregularidad territorial. Resulta difícil apreciar pautas espaciales en los datos, aunque los valores cercanos a 10 suelen aparecer en las cercanías del mar (Tocopilla, Quillagua), y más infrecuentemente en las alturas (a excepción de Parinacota Conaf o Conchi muro embalse). No obstante, no se descarta de antemano que la importancia de la repetición decenal sea en realidad un doblete de un período quinquenal. Esta última pauta sí se mantiene en mayor número de estaciones. Si nos atenemos a los valores del primer período los contajes son los siguientes:

En torno a 20: 7 casos (CÑ , GR, IN, OS, OS, $\mathrm{RQ}, \mathrm{SP}, \mathrm{VI})$

En torno a 15: 12 casos (CI, CO, CV, HU, OG, PN, PT, SA, SE, TE, TN, VR) 
Tabla 5. Tests de aleatoriedad de los datos originales ( $\mathrm{t}$ ) y completados ( $\mathrm{T})$; períodos ( $\mathrm{P}$ en años).

\begin{tabular}{|c|c|c|c|c|c|c|c|c|c|c|c|c|c|}
\hline Id & t1 & $\mathrm{t} 2$ & $\mathbf{t 3}$ & $\mathbf{r}$ & T1 & T2 & T3 & $\mathbf{R}$ & P1 & $\mathbf{P 2}$ & P3 & P4 & P5 \\
\hline $\mathbf{A C}$ & Sí & No & No & No & No & No & Sí & No & 2,34 & 2,28 & 13,7 & 32 & \\
\hline $\mathbf{A H}$ & Sí & Sí & Sí & Sí & & & & & & & & & \\
\hline $\mathbf{A L}$ & No & Sí & Sí & No & Sí & Sí & Sí & Sí & 4,5 & 5,62 & 22,5 & 11,3 & \\
\hline AN & Sí & Sí & Sí & Sí & Sí & Sí & Sí & Sí & 63 & 7,87 & 2,17 & 3,5 & \\
\hline AO & Sí & No & Sí & No & Sí & No & Sí & No & 5,72 & 2,12 & 2,23 & & \\
\hline $\mathbf{A Q}$ & Sí & Sí & Sí & Sí & & & & & & & & & \\
\hline AS & No & Sí & No & No & Sí & Sí & Sí & Sí & 4,09 & 15 & 22,5 & 2,25 & 7,5 \\
\hline AT & No & No & No & No & Sí & Sí & Sí & Sí & 5,09 & 18,7 & 3,29 & 3,73 & \\
\hline $\mathbf{A V}$ & Sí & No & No & No & Sí & Sí & Sí & Sí & 47 & 6,71 & 3,61 & 2,13 & 5,22 \\
\hline $\mathbf{A Y}$ & Sí & No & Sí & & Sí & Sí & Sí & Sí & 5,87 & 3,61 & 4,27 & 47 & \\
\hline $\mathbf{A Z}$ & Sí & No & Sí & No & Sí & No & Sí & No & 2,76 & 22,5 & 4,27 & 4,7 & 6,71 \\
\hline BA & Sí & No & Sí & No & No & No & Sí & No & & & & & \\
\hline $\mathbf{B E}$ & & & & & Sí & Sí & Sí & Sí & 12 & 24 & 4 & 5,33 & \\
\hline BQ & No & No & Sí & No & Sí & Sí & Sí & Sí & 3,61 & 5,22 & 2,35 & 23,5 & \\
\hline CA & No & No & No & No & & & & & & & & & \\
\hline CB & Sí & No & No & No & Sí & Sí & Sí & Sí & 9 & 5,62 & 15 & 6,42 & 2,25 \\
\hline $\mathrm{CC}$ & Sí & No & Sí & No & Sí & Sí & Sí & Sí & 13,3 & 4,07 & 53 & 3,11 & \\
\hline CD & Sí & Sí & Sí & Sí & Sí & Sí & Sí & Sí & 12,5 & 3,57 & 3,84 & 2,27 & \\
\hline $\mathrm{CH}$ & & & & & Sí & Sí & Sí & Sí & 8,5 & 17 & 4,25 & & \\
\hline CI & Sí & Sí & Sí & Sí & Sí & Sí & Sí & Sí & 15,7 & 7,83 & 3,61 & 2,47 & \\
\hline CL & No & No & No & No & Sí & Sí & Sí & Sí & 9,4 & 4,27 & 3,91 & 2,23 & \\
\hline $\mathbf{C M}$ & No & No & No & No & Sí & No & No & No & 45 & 11,3 & 5,62 & 3,46 & \\
\hline $\mathrm{CN}$ & & & & & Sí & No & Sí & No & 17 & 8,5 & & & \\
\hline $\mathbf{C} \tilde{\mathbf{N}}$ & Sí & No & No & No & Sí & Sí & Sí & Sí & 24 & 12 & 6 & 4 & 2,52 \\
\hline $\mathrm{CO}$ & Sí & No & Sí & No & Sí & Sí & Sí & Sí & 16,5 & 33 & 3,66 & 3,3 & 4,12 \\
\hline CP & No & No & Sí & No & Sí & Sí & Sí & Sí & 5 & 15 & & & \\
\hline CQ & Sí & No & Sí & No & Sí & Sí & Sí & Sí & 3,78 & 3,25 & 10,6 & & \\
\hline CR & Sí & Sí & Sí & Sí & Sí & Sí & Sí & Sí & 13,3 & 2,85 & 40 & 5 & \\
\hline CS & Sí & Sí & Sí & Sí & Sí & Sí & Sí & Sí & 5,62 & 15 & 4,09 & 9 & 2,81 \\
\hline $\mathbf{C U}$ & Sí & Sí & Sí & Sí & No & Sí & Sí & No & 15 & 5,62 & 4,09 & 45 & \\
\hline $\mathrm{CV}$ & & & & & Sí & Sí & Sí & Sí & 2,05 & 20,5 & 2,27 & & \\
\hline $\mathbf{C X}$ & Sí & Sí & Sí & Sí & Sí & Sí & Sí & Sí & 6,33 & 2,23 & 12,7 & 2,53 & \\
\hline $\mathrm{CY}$ & & & & & & & & & 2,28 & 8 & 3,2 & & \\
\hline EN & Sí & No & Sí & No & Sí & Sí & Sí & Sí & 2,2 & 6,6 & 3,3 & 5,5 & \\
\hline EN & & & & & Sí & Sí & Sí & Sí & 13,3 & 3,63 & 5 & 2,22 & \\
\hline ET & Sí & Sí & Sí & Sí & Sí & Sí & Sí & Sí & 13,7 & 5,12 & 5,85 & 8,2 & \\
\hline
\end{tabular}




\begin{tabular}{|c|c|c|c|c|c|c|c|c|c|c|c|c|c|}
\hline Id & $\mathbf{t 1}$ & $\mathbf{t} 2$ & $\mathbf{t} 3$ & $\mathbf{r}$ & T1 & $\mathbf{T 2}$ & T3 & $\mathbf{R}$ & $\mathbf{P 1}$ & $\mathbf{P 2}$ & P3 & P4 & P5 \\
\hline GD & Sí & Sí & Sí & Sí & Sí & Sí & Sí & Sí & 13,3 & 2,5 & 5,71 & 3,63 & 3,07 \\
\hline GR & No & No & No & No & Sí & Sí & Sí & Sí & 23,5 & 6,71 & 9,4 & 3,35 & \\
\hline GU & Sí & Sí & Sí & Sí & Sí & Sí & Sí & Sí & 5,42 & 3,45 & 38 & & \\
\hline HU & Sí & No & Sí & No & Sí & Sí & Sí & Sí & 16,5 & 2,53 & 5,5 & & \\
\hline IB & Sí & Sí & Sí & Sí & Sí & Sí & Sí & Sí & 13,3 & 4,07 & 53 & 7,57 & \\
\hline IN & Sí & Sí & Sí & Sí & Sí & Sí & Sí & Sí & 22,5 & 2,25 & 3,75 & 11,3 & \\
\hline IQ & Sí & Sí & Sí & Sí & Sí & Sí & Sí & Sí & 2,38 & 10 & 5,16 & 3,1 & \\
\hline $\mathrm{IQm}$ & 1 & No & Sí & No & & & & & 2,49 & 9 & 3,07 & & \\
\hline LG & & & & & No & Sí & Sí & No & 5,33 & 2,91 & 3,4 & & \\
\hline $\mathbf{L L}$ & Sí & Sí & Sí & Sí & & & & & & & & & \\
\hline LQ & Sí & Sí & Sí & Sí & Sí & Sí & No & No & 45 & 22,5 & 9 & & \\
\hline $\mathbf{L Z}$ & Sí & Sí & Sí & Sí & Sí & Sí & Sí & Sí & 5,12 & 13,7 & 8,2 & 3,41 & \\
\hline MM & No & No & Sí & No & & & & & & & & & \\
\hline MU & Sí & Sí & Sí & Sí & & & & & 12,7 & 3,45 & & & \\
\hline MX & & & & & Sí & Sí & Sí & Sí & 4 & 3,6 & 6 & 36 & \\
\hline OG & No & No & No & No & Sí & Sí & No & No & 15 & 45 & 4,5 & & \\
\hline OS & & & & & No & Sí & Sí & No & 22,5 & 11,3 & 5 & 4,09 & \\
\hline PA & & & & & Sí & Sí & Sí & Sí & 3,33 & 4 & 10 & & \\
\hline PC & Sí & Sí & Sí & Sí & Sí & Sí & Sí & Sí & 5,3 & 13,3 & 10,6 & 3,78 & \\
\hline PE & Sí & Sí & Sí & Sí & Sí & Sí & Sí & Sí & 13,3 & 4,41 & 53 & 5,3 & 2,78 \\
\hline PL & & & & & Sí & Sí & Sí & Sí & 2,75 & & & & \\
\hline PM & No & Sí & No & No & No & Sí & No & No & & & & & \\
\hline PN & Sí & Sí & Sí & Sí & Sí & Sí & Sí & Sí & 13,3 & 3,07 & 8 & 5 & \\
\hline PO & & & & & No & Sí & Sí & No & 3,45 & 38 & 5,42 & 12,7 & \\
\hline $\mathbf{P Q}$ & Sí & No & Sí & No & & & & & & & & & \\
\hline PS & Sí & Sí & Sí & Sí & & & & & 3,58 & 14,3 & 4,77 & & \\
\hline PT & & & & & No & No & Sí & No & 9,2 & 46 & 3 & 2,45 & \\
\hline PZ & & & & & Sí & Sí & Sí & Sí & 3 & & & & \\
\hline QM & Sí & Sí & Sí & Sí & & & & & 3,8 & & & & \\
\hline $\mathbf{Q U}$ & Sí & No & Sí & No & 1 & No & Sí & No & 11,8 & 7,83 & 3,91 & 3,61 & 2,23 \\
\hline RG & & & & & & & & & 12,7 & 3,45 & 5,42 & 2,53 & \\
\hline $\mathbf{R L}$ & Sí & Sí & Sí & Sí & Sí & Sí & Sí & Sí & 6,62 & 3,46 & 9 & 2,25 & \\
\hline RQ & & & & & Sí & Sí & Sí & Sí & 20,5 & 5,12 & 4,1 & 8,2 & \\
\hline RS & Sí & Sí & Sí & Sí & Sí & No & Sí & No & 3,72 & 13,7 & 5,12 & 2,15 & \\
\hline RT & No & Sí & Sí & No & Sí & Sí & Sí & Sí & 12 & 24 & 3,42 & 4,36 & \\
\hline SA & Sí & No & Sí & No & & & & & 15 & 5 & & & \\
\hline $\mathbf{S C}$ & No & Sí & Sí & No & Sí & Sí & Sí & Sí & 13,3 & 2,85 & 40 & 3,07 & 5,71 \\
\hline SE & Sí & Sí & Sí & Sí & Sí & Sí & Sí & Sí & 15 & 9 & 3,75 & 2,81 & 5,62 \\
\hline
\end{tabular}




\begin{tabular}{|c|c|c|c|c|c|c|c|c|c|c|c|c|c|}
\hline Id & t1 & t2 & $\mathbf{t 3}$ & $\mathbf{r}$ & $\mathbf{T 1}$ & $\mathbf{T} 2$ & T3 & $\mathbf{R}$ & P1 & P2 & P3 & P4 & P5 \\
\hline SG & 1 & No & Sí & No & 1 & No & Sí & No & 5 & 4 & 10 & 2,22 & \\
\hline SI & Sí & No & Sí & No & Sí & Sí & Sí & Sí & 6,83 & 3,72 & 13,7 & 4,55 & \\
\hline SP & & & & & Sí & Sí & Sí & Sí & 22,5 & 5 & 4,09 & 11,3 & \\
\hline TC & Sí & Sí & Sí & Sí & Sí & Sí & Sí & Sí & 13,3 & 5 & 2,85 & & \\
\hline TE & Sí & Sí & Sí & Sí & No & Sí & Sí & No & 13,3 & 40 & 3,07 & 5 & \\
\hline TI & Sí & Sí & Sí & Sí & Sí & Sí & Sí & Sí & 12 & 24 & 3,69 & 5,33 & \\
\hline TL & Sí & No & Sí & No & Sí & Sí & Sí & Sí & 13,3 & 5,71 & 4 & 3,63 & 2,66 \\
\hline $\mathbf{T N}$ & Sí & Sí & Sí & Sí & Sí & Sí & Sí & Sí & 15 & 5,62 & 45 & 4,5 & \\
\hline $\mathbf{T P}$ & 1 & No & Sí & No & No & No & Sí & No & 2,61 & 6,71 & 47 & 15,7 & 3,13 \\
\hline TR & Sí & Sí & Sí & Sí & Sí & Sí & Sí & Sí & 13,7 & 4,1 & 41 & & \\
\hline TT & & & & & Sí & Sí & Sí & Sí & 4,7 & 7,83 & 2,13 & & \\
\hline UA & & & & & Sí & Sí & Sí & Sí & & & & & \\
\hline UJ & & & & & No & Sí & Sí & No & 3,6 & 18 & 6 & & \\
\hline VI & No & Sí & Sí & No & No & Sí & Sí & No & 22,5 & 9 & 4,5 & 3,46 & \\
\hline VR & & & & & Sí & Sí & Sí & Sí & 46 & 4,18 & 3,83 & 9,2 & 15,3 \\
\hline $\mathbf{X A}$ & No & Sí & No & No & Sí & Sí & Sí & Sí & 4,07 & 13,3 & 3,11 & & \\
\hline XB & Sí & Sí & Sí & Sí & Sí & Sí & Sí & Sí & 2,05 & 3,72 & 3,15 & 6,8 & \\
\hline XI & & & & & Sí & Sí & Sí & Sí & 3,6 & 4 & 6 & & \\
\hline XL & Sí & No & Sí & No & No & No & No & No & 47 & 6,71 & 4,27 & 2,76 & \\
\hline $\mathbf{X N}$ & Sí & Sí & Sí & Sí & Sí & Sí & Sí & Sí & 2,73 & 2,05 & 5,12 & 5,85 & 10,3 \\
\hline $\mathbf{X} \tilde{\mathbf{N}}$ & Sí & No & Sí & No & & & & & & & & & \\
\hline $\mathbf{X P}$ & No & No & No & No & Sí & Sí & Sí & Sí & 3,63 & 13,3 & 2,22 & & \\
\hline XR & No & No & No & No & Sí & No & Sí & No & 5,3 & 3,11 & 13,3 & 4,41 & \\
\hline $\mathbf{X Y}$ & No & No & No & No & Sí & Sí & Sí & Sí & 3,05 & 4,23 & 13,8 & 5,5 & 3,66 \\
\hline $\mathbf{X Z}$ & & & & & Sí & Sí & Sí & Sí & 2,2 & 16,5 & 11 & 6,6 & \\
\hline YS & Sí & No & Sí & No & Sí & Sí & Sí & Sí & 2,93 & 4,4 & 8,8 & 2,31 & \\
\hline
\end{tabular}

Siglas empleadas: Id = identificación; $\mathrm{t} 1, \mathrm{t} 2, \mathrm{t} 3=$ test $1^{\circ}, 2^{\circ}$ y $3^{\circ} ; \mathrm{r}=$ resultado para los datos originales; $\mathrm{T} 1, \mathrm{~T} 2, \mathrm{~T} 3=$ test $1^{\circ}, 2^{\circ}$ y $3^{\circ}$; $\mathrm{R}=$ resultado para los datos completados. $\mathrm{P} 1$ a $5=$ períodos (en años) $1^{\circ}$ a $5^{\circ}$ de los periodogramas, en orden decreciente de señal.

En torno a 13 hay 23 casos (BE, CC, CD, CR, EÑ, ET, GD, IB, LQ, MU, MX, PE, PN, PO, RG, RT, SC, SE, TC, TE, TI, TL, TR)

En torno a 10: 6 casos (CB, CH, CL, PT, QU, TL)

En torno a 5: 17 menciones (AL, AO, AT, AY, CP, CS, CX, GU, LG, LZ, PC, RÑ, RS, SG, SI, TT, XL)

En torno a 4: BQ, CQ, MX, QM, QU, RS, TP, $\mathrm{XA}, \mathrm{XI}=9$ casos

Próximos a 3 hay 9 casos: PA, PL, PO, PS, PZ, TC, TP, UJ, XN
En torno a 2: 7 casos: $\mathrm{AC}, \mathrm{XB}, \mathrm{CV}, \mathrm{CY}, \mathrm{EN}$, IQ, IQ mezcla

A modo de ejemplo de periodograma en el que se aprecia la fuerza (medida en la ordenada) de la señal del período (valor inverso a la frecuencia) consideramos las figuras de Conchi embalse y Putre (Gráfico 7).

Si se trabaja con todos los períodos detectados en las 5 primeras clases se alcanzan 460 datos que se analizan en el histograma siguiente, de 77 clases de año en año, comenzando por 2 y terminando por 79 . 
Gráfico 7. Periodograma de las estaciones Conchi embalse y Putre.
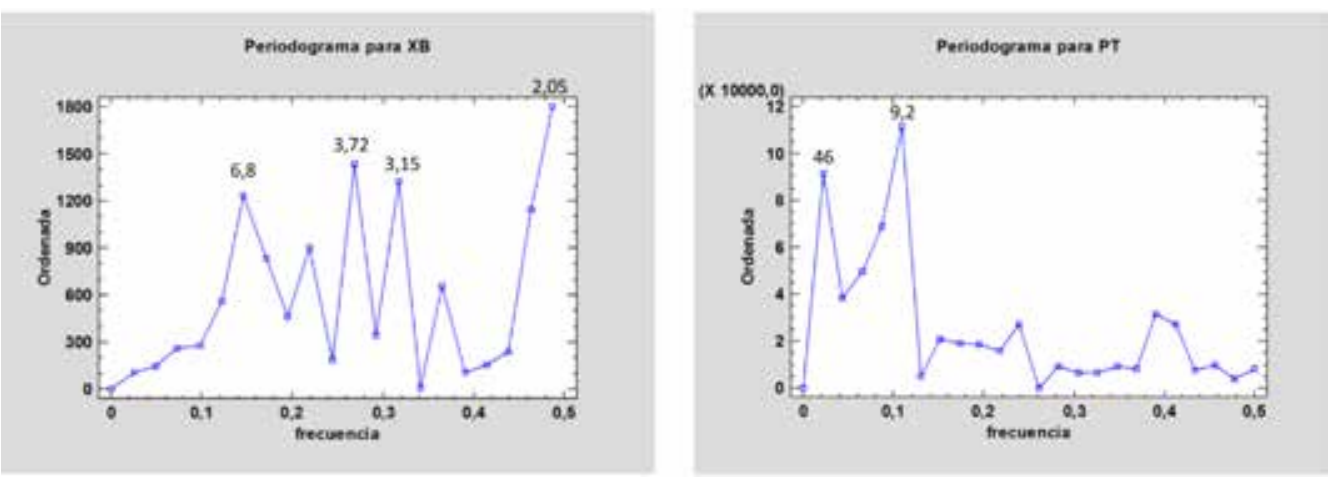

Gráfico 8. Histograma de frecuencias de todos los períodos detectados.

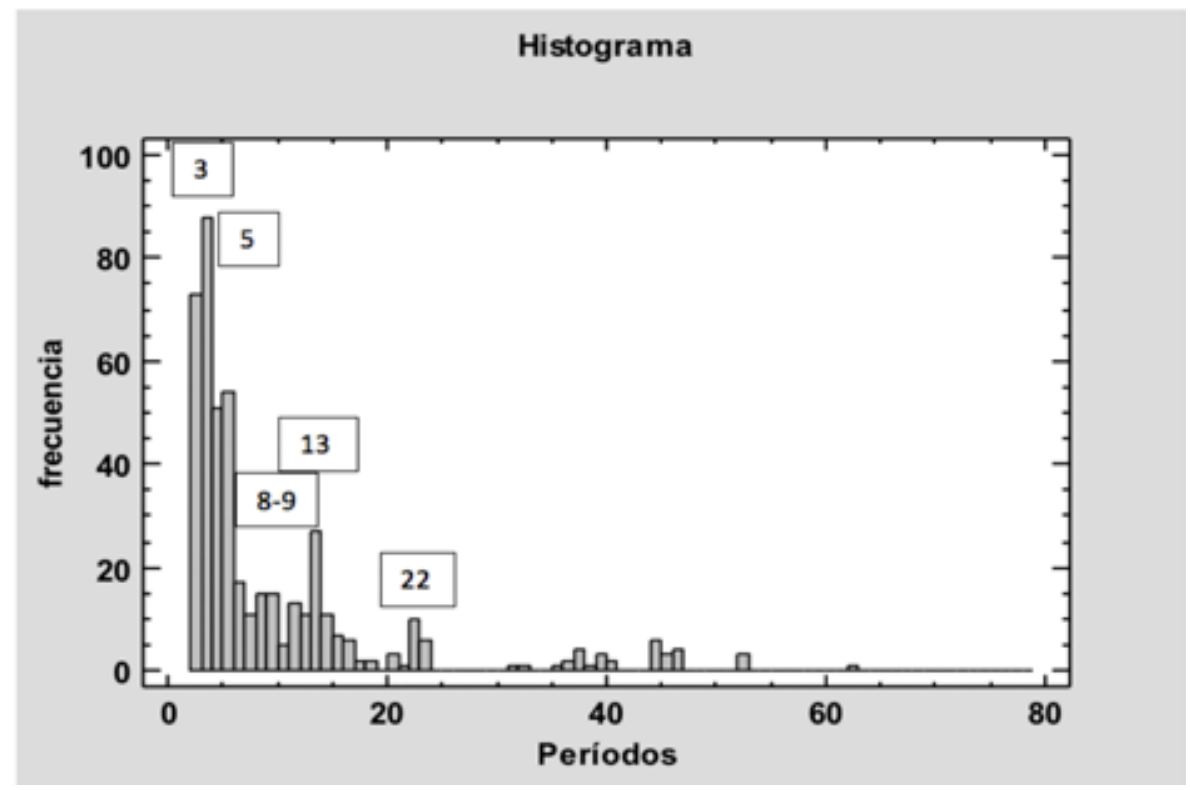

Destaca la gran cantidad de períodos entre 3,01-4 años con 88 casos (19,31\%), los de 5,01-6 con el $11,74 \%$, los de las clases 8 y 9 , ambos igualados al $3,26 \%$, el 13 con el $5,76 \%$ y el 22 con $2,17 \%$, como se puede observar en el Gráfico 8.

Si se exponen solo los valores del período más pronunciado ( $1^{\mathrm{er}}$ período) para 125 datos, se ve la misma pauta de importancia máxima de la clase de 3 años (18 casos, 14,4\%), inmediatamente seguida de la de 13 (17 casos, 13,6\%), bastante destacadas de las de 5 (11 ocurrencias, con $8,8 \%$ ) y de 4 y 12 (7,2 y 4\%, respectivamente), Gráfico 9 .
He aquí los principales resultados del análisis de los estilos pluviométricos de las estaciones norchilenas, en las que, lejos de manifestarse esquemáticas tendencias, la señal ofrece gran complejidad que reta a un desentrañado ulterior.

\section{Conclusiones}

Tras haber sometido los datos a un rellenado de las series faltantes se ha podido operar en la determinación de componentes no aleatorios, sino rítmicos, en las precipitaciones de las tres regiones 


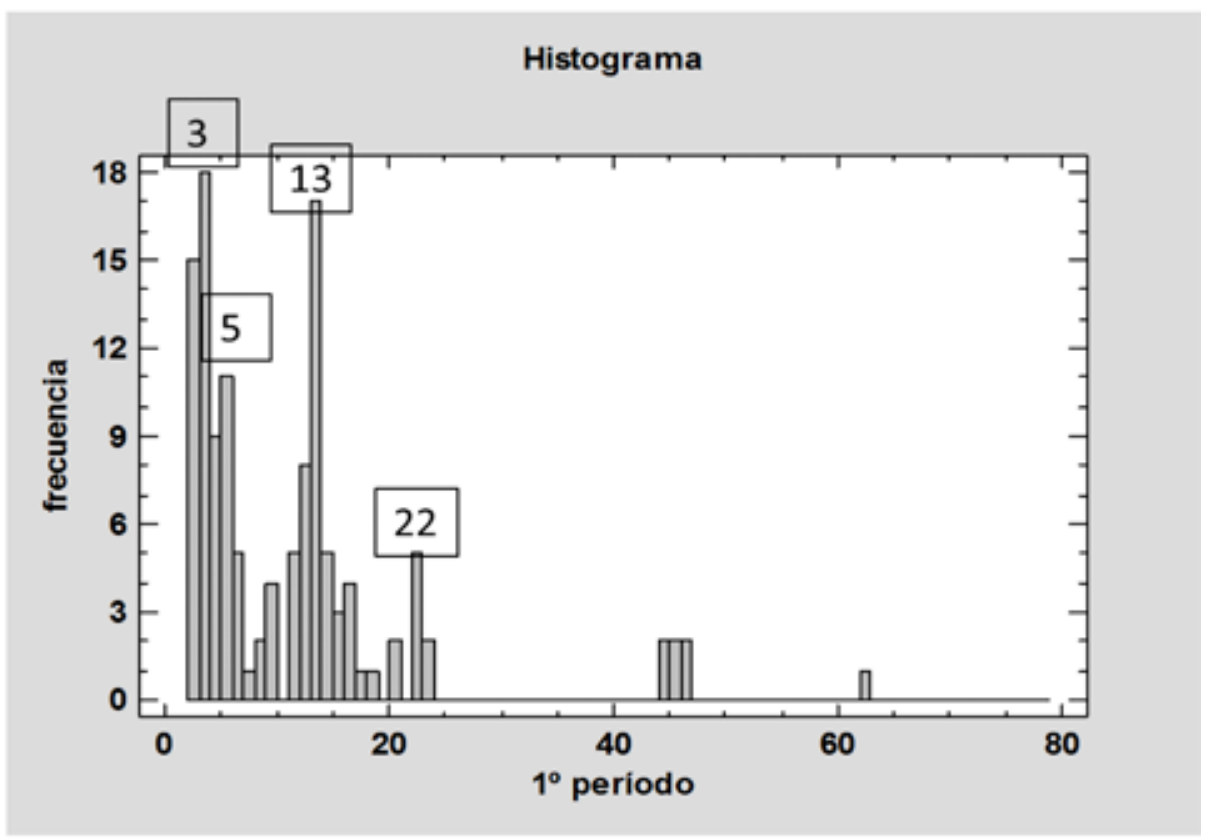

más septentrionales chilenas. Se ha constatado que, lejos de una tendencia, en exceso general, se destacan las repeticiones a los 3, 5, 8-9, 13 y 22 años que habrán de cotejarse con los posibles mecanismos de producción de lluvia ya establecidos.

\section{Agradecimientos}

Los autores agradecen el patrocinio del Proyecto Fondecyt 1150701: Investigación participativa a través de observatorios ecológico-sociales de los cambios y variabilidades climáticas del altiplano andino del Norte de Chile y del Proyecto Heidelberg Center para Latinoamérica: Gobernanza de Riesgos y Recursos. Asimismo, reconocen la colaboración de la sección Recursos Hídricos de la Dirección General de Aguas de Chile, con la proporción de los datos actualizados de las estaciones meteorológicas analizadas en el presente trabajo.

\section{Referencias Citadas}

Aceituno, P.

1996 Elementos del clima en el altiplano sudamericano, Revista de Geofísica, 44, 37-55.

Christie, D. A., Lara, A., Barichivich, J., Villalba, R., Morales. M.S. y Cuq, E.

2009 El Niño-Southern Oscillation signal in the world's highest-elevation tree-ring chronologies from the Altiplano, Central Andes, Palaeogeography, Palaeoclimatology, Palaeoecology, 281, 309-319.

Garreaud, R.

2000 Intraseasonal Variability of Moisture and Rainfall over the South American Altiplano, Monthly Weaather Review, 128, 3338-46.

Garreaud, R. y Aceituno, P.

2001 Interannual Rainfall Variability over the South American Altiplano, Journal of Climate, 14, 2779-89.
Garreaud, R., Vuille, M.y Clement, A. M.

2003 The climate of the Altiplano: observed current conditions and mechanisms of past changes, Palaeogeography, Palaeoclimatology, Palaeoecology, 194, 5-22.

Cedex, Centro de Estudios y Experimentación de Obras Públicas, del Ministerio de Fomento

2013 Manual Chac. Cálculo hidrometeorológico de aportaciones y crecidas. Madrid, 76 págs.

Romero, H., Smith, P., Mendonça, M. y Méndez, M.

2013 Macro y mesoclimas del altiplano andino y desierto de Atacama: desafíos y estrategias de adaptación social ante su variabilidad, Revista de Geografía Norte Grande, 55, 19-41.

Sanz Donaire, J.J.

2010 Tendencias de la precipitación sobre Argentina (18712009). Boletín de la Real Sociedad Geográfica, Madrid, 146, 189-202. 


\section{Sanz Donaire, J. J.}

2012 Las series anuales de precipitación más largas de Chile: estudio y enseñanzas. Estudios Geográficos, Madrid, Vol. $73, \mathrm{~N}^{\circ} 273,625-656$.
Sarricolea Espinoza, P. y Romero Aravena, H.

2015 Variabilidad y cambios climáticos observados y esperados en el Altiplano del norte de Chile, Revista de Geografía Norte Grande, 62, 169-183.

\section{Nota}

1 Solemos distinguir entre "datos" y "valores", los primeros registrados -que nos vienen dados-y los restantes calculados o estimados, pero valorados. 